\title{
A sensitivity analysis of Ring effect to aerosol properties and comparison to satellite observations
}

\author{
T. Wagner ${ }^{1}$, S. Beirle ${ }^{1}$, T. Deutschmann ${ }^{2}$, and M. Penning de Vries ${ }^{1}$ \\ ${ }^{1}$ Max-Planck-Institute for Chemistry, Mainz, Germany \\ ${ }^{2}$ Institute for Environmental Physics, University of Heidelberg, Heidelberg, Germany \\ Received: 24 July 2010 - Published in Atmos. Meas. Tech. Discuss.: 19 August 2010 \\ Revised: 7 December 2010 - Accepted: 10 December 2010 - Published: 16 December 2010
}

\begin{abstract}
In this study we explore the sensitivity of satellite observations of the Ring effect (at various wavelengths) to atmospheric aerosol properties. Compared to clouds, aerosols have a rather weak influence on the Ring effect, thus the requirements on the accuracy of the measurements and the radiative transfer simulations are high. In this study, we show that for moderate and high aerosol optical depth (AOD), Ring effect observations are sensitive enough to yield information not only on the AOD, but also on the absorbing properties of aerosols and the aerosol layer height. The latter two quantities are especially important for the determination of the radiative effects of aerosols.

Our investigations are based on observations by the satellite instrument SCIAMACHY on ENVISAT (2004-2008) and on model simulations using the Monte-Carlo radiative transfer model McArtim. In addition to the Ring effect we investigate the impact of aerosols on the absorptions of the oxygen molecule $\left(\mathrm{O}_{2}\right)$ and dimer $\left(\mathrm{O}_{4}\right)$ as well as the radiance. In general good consistency between measured and simulated quantities is found. In some cases also systematic differences occurred, which are probably mainly related to the strong polarisation sensitivity of the SCIAMACHY instrument.

Our study indicates that Ring effect observations have important advantages for aerosol retrievals: they can be analysed with high accuracy in various wavelength ranges; and depending on the wavelength range, they show different sensitivities on aerosol properties like single scattering albedo, optical depth or layer height. The results of this study are of particular interest for future aerosol inversion algorithms for
\end{abstract}

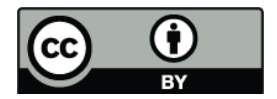

Correspondence to: T. Wagner (thomas.wagner@mpic.de) satellite instruments with reduced polarisation sensitivity and smaller ground pixels, capable of measuring the Ring effect with higher accuracy.

\section{Introduction}

The Ring effect describes the so-called "filling-in" of solar Fraunhofer lines in the spectra of scattered sun light compared to direct sun light observations. It was first observed by Shefov (1959) and Grainger and Ring (1962). Today, it is commonly agreed that rotational Raman scattering on atmospheric molecules is the dominant source for the Ring effect (e.g. Kattawar et al., 1981; Solomon et al., 1987). The extent of the filling-in of Fraunhofer lines depends on the number of molecular scatter events, and hence, on the presence and properties of clouds and aerosols. The dominant effect of clouds and aerosols is that they shield the atmosphere below and thus reduce the probability of the observed photons being scattered by air molecules. The occurence of Raman scattering therefore generally decreases with increasing cloud altitude. Several algorithms for the determination of cloud top pressure from satellite observations of the Ring effect were developed in recent years and were successfully applied to observations from the TOMS, GOME, and OMI instruments (Park et al., 1986; Joiner et al., 1995, 2002, 2004, 2010; Joiner and Bhartia, 1995; de Beek et al., 2001; Joiner and Vasilkov, 2006; van Deelen et al., 2008).

The shielding effect of clouds is also exploited in cloud algorithms based on the absorption of the oxygen molecule $\mathrm{O}_{2}$ and dimer $\mathrm{O}_{4}$ (e.g. Kuze and Chance, 1994; Koelemeijer et al., 2001, 2003; de Beek et al., 2001; Acarreta et al., 2004; Kokhanovsky et al., 2005, 2007; Wagner et al., 2008). 
In principle, aerosols influence atmospheric radiative transfer in a similar way as clouds do, but the influence of aerosols is usually much weaker, because aerosols usually have much smaller optical depth (AOD) and are typically located close to the surface. Another important difference between clouds and aerosols is that especially in the UV aerosols can absorb a significant fraction of the solar radiation.

Three basic effects of aerosols can be distinguished (see also Fig. 1)

\section{a. Albedo effect}

Due to the enhanced scattering caused by the aerosol particles, the light path lengths in the lower atmosphere are increased compared to the aerosol-free case. Since this effect is very similar to the influence of an increased surface albedo it is often referred to as albedo effect. As we will show later, the influence of the albedo effect on the Ring effect is fundamentally different compared to that on the absorptions of $\mathrm{O}_{2}$ and $\mathrm{O}_{4}$ (see also Sect. 4.3). It should be also noted that, in contrast to the effect of clouds, in the presence of aerosols the backscattered radiance can be even smaller than for the aerosol-free case (for strongly absorbing aerosols with a single scattering albedo smaller than about 0.8 ).

b. Shielding effect

Additional aerosol scattering shields the atmosphere below, leading to a decrease of the strength of the Ring effect and also of trace gas absorptions like those of $\mathrm{O}_{2}$ and $\mathrm{O}_{4}$.

\section{c. Aerosol absorption}

For strongly absorbing aerosols in many cases the shielding effect can become especially strong, because radiation from below the aerosol layer is partly absorbed by the aerosols. Also the atmospheric light path lengths are reduced by aerosol absorption.

In this paper, we systematically investigate the effects of aerosols on various retrieved quantities: besides the Ring effect at different wavelengths, also the absorptions of $\mathrm{O}_{2}$ and $\mathrm{O}_{4}$, and on the measured radiance are investigated. Since the observed quantities also strongly depend on the satellite's viewing geometry, the effects of viewing angle and solar zenith angle are also investigated. It should be noted that similar initial studies have been conducted by Vasilkov and co-workers (2006).

Whenever possible, we use both, measurements and model simulations to determine the dependencies of the observed quantities on aerosol properties and viewing geometry. This is performed for the effects of AOD, aerosol layer height, viewing angle and solar zenith angle. The influence of the aerosol single scattering albedo (SSA) and asymmetry parameter $(g)$ is investigated only by radiative transfer simulations.

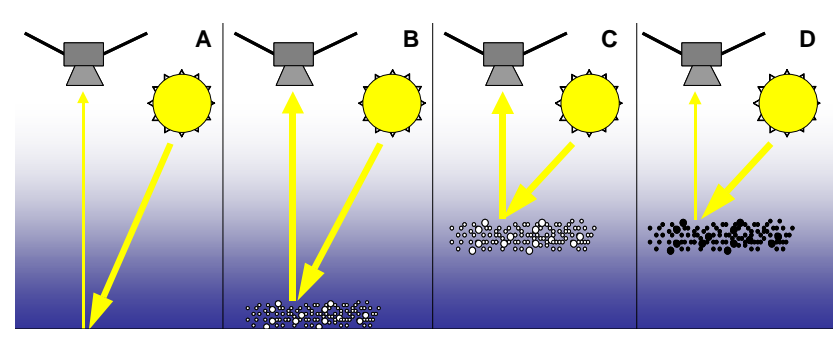

Fig. 1. Basic effects of aerosols on the atmospheric radiative transfer. Albedo effect: compared to an aerosol-free atmosphere (A), in the presence of aerosols the effective earth's albedo is increased leading to a higher probability of the observed photons to have "seen" the lower atmosphere (B). Shielding effect: additional scattering by aerosols causes a reduction of the light path lengths below the aerosol layer (C). In contrast to clouds, aerosols with single scattering $<1$ may also absorb a substantial fraction of the solar photons (D).

The paper is organised as follows: in Sect. 2 information on the SCIAMACHY instrument and the algorithms for the retrieval of the Ring effect, the $\mathrm{O}_{2}$ and $\mathrm{O}_{4}$ absorptions, and the normalised radiance is presented. Section 3 introduces the radiative transfer model, which is used for the simulation of the measured quantities. In Sect. 4, the modelled and measured dependencies of the Ring effect and $\mathrm{O}_{2}$ and $\mathrm{O}_{4}$ absorptions on the observational geometry (solar zenith angle and viewing angle) and aerosol properties (AOD, SSA, $g$, and layer height) are discussed. Section 5 presents a summary of the main findings of our study and an outlook on future applications.

\section{Instrument and data analysis}

We chose observations of the satellite instrument SCIAMACHY on ENVISAT (Burrows et al., 1995, Bovensmann et al., 1999) for this study, because it provides continuous spectra of the earth shine radiance with moderate spectral resolution. Thus the Ring effect can be analysed with high accuracy in different spectral ranges. In addition, absorptions by $\mathrm{O}_{4}$ and $\mathrm{O}_{2}$ can be analysed.

It should be noted that continuous spectra with moderate spectral resolution are also available from other satellite instruments like GOME-1 on ERS-2, GOME-2 on METOP, and OMI on AURA. Of these instruments, OMI would be the most suitable for the analysis of the Ring effect, due to its high spatial resolution and the fact that it is almost insensitive to polarisation. However, because the instrument's spectral range ends at $500 \mathrm{~nm}$, no measurement of the $\mathrm{O}_{2}$ absorption in the red and near IR spectral range is possible. We therefore used SCIAMACHY for this study, as it has the next-best spatial resolution. 


\subsection{SCIAMACHY instrument}

In 2002 the SCanning Imaging Absorption SpectroMeter for Atmospheric ChartographY (SCIAMACHY) (Burrows et al., 1995; Bovensmann et al., 1999) was launched on board of ENVISAT. It consists of a set of eight spectrometers that simultaneously measure sunlight reflected from the Earth's surface and atmosphere. SCIAMACHY's eight spectral windows cover the wavelength range between $240 \mathrm{~nm}$ and $2380 \mathrm{~nm}$ with moderate spectral resolution $(0.2-1.2 \mathrm{~nm}$ full width at half maximum, FWHM). The satellite operates in a nearly polar, sun-synchronous orbit at an altitude of about $800 \mathrm{~km}$ with a local equator crossing time at approximately 10:00 a.m. While the satellite orbits in an almost north-south direction, the SCIAMACHY instrument scans the surface in the perpendicular, east-west direction during daytime. Global coverage is achieved after 6 days at the equator. At higher latitudes better coverage is achieved because of the partial overlap of neighbouring orbits. SCIAMACHY operates in different viewing modes: nadir, limb, and occultation. In the standard operation mode, alternating limb and nadir measurements are performed. In this study, only nadir observations with a ground pixel size of $30 \times 60 \mathrm{~km}^{2}$ are used. Due to this rather coarse spatial resolution, the probability for cloud contamination is rather high (Krijger et al., 2007). This constitutes an important limitation for the retrieval of aerosol properties from SCIAMACHY.

Another important property of the SCIAMACHY instrument is its strong polarisation sensitivity. As shown in Fig. 2, this sensitivity varies with wavelength and is especially high in the UV spectral range. Because the spectral features of polarisation and the Ring effect are highly correlated (see e.g. Aben et al., 2003), the retrieval of the Ring effect is affected by the (varying) degree of polarisation of the measured scattered sun light. This problem is further complicated by the fact that the polarisation sensitivity of SCIAMACHY also changes with time.

\subsection{Data analysis}

The raw satellite spectra are analysed using differential optical absorption spectroscopy (DOAS, see Platt and Stutz, 2008). For the analysis of the Ring effect and of $\mathrm{O}_{2}$ and $\mathrm{O}_{4}$ absorption, we selected spectral intervals in which the relevant reference spectrum shows strong and characteristic spectral features. In addition, spectra of all other relevant spectral features in the respective wavelength ranges (trace gas absorptions, Ring spectra, and instrumental features) are included in the spectral fitting procedure. To account for broad band spectral dependencies of surface reflection and scattering on aerosols and cloud particles, a low order polynomial is included. The specific settings and the reference spectra for the different spectral analyses are summarised in Table 1 and described in detail in the following sub-sections.

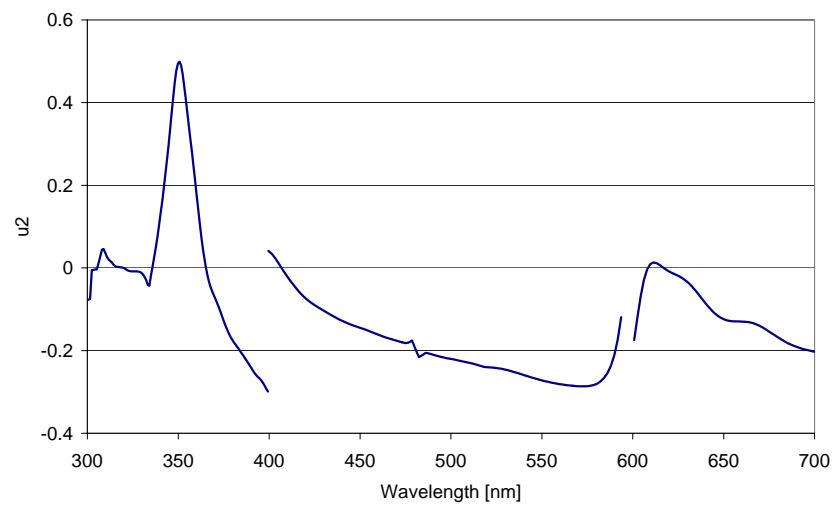

Fig. 2. Illustration of the wavelength dependent polarisation sensitivity of the SCIAMACHY instrument. Displayed is the so-called $\boldsymbol{u} 2$-vector, the ratio of the Müller matrix elements for one polarisation direction and unpolarised light (Slijkhuis et al., 1999). The $\boldsymbol{u} 2$ vector is based on the version 3.1 keydata (Noël et al., 2005).

\subsubsection{Ring effect analysis}

The analysis of the Ring effect is performed in four different fitting windows in the UV and the blue part of the spectrum, where the filling-in of the solar Fraunhofer lines is particularly strong. The different analyses are referred to as $335 \mathrm{~nm}, 350 \mathrm{~nm}, 380 \mathrm{~nm}$, and $430 \mathrm{~nm}$, according to the centre of the chosen wavelength range, as given in Table 1. Apart from the different wavelength ranges, also different choices of reference spectra are used. For the analyses at $335 \mathrm{~nm}, 350 \mathrm{~nm}$, and $380 \mathrm{~nm}$ more than one Ring spectrum was included in the spectral fitting procedure: in addition to the "standard" Ring spectrum, calculated for a pure Rayleigh scattering atmosphere, a second Ring spectrum representative for the presence of clouds and aerosols was included (for details see Wagner et al., 2009a). For the analyses at $350 \mathrm{~nm}$ and $380 \mathrm{~nm}$, a Ring spectrum for vibrational Raman scattering in water was also included (Vasilkov et al., 2002; Vountas et al., 2003). Since these additional Ring spectra show a high degree of correlation to the "standard" Ring spectrum, they were ortho-normalised with respect to the standard Ring spectrum prior to the spectral fitting procedure. This ortho-normalisation was performed for the different wavelength ranges in such a way that at the wavelengths of interest $(335 \mathrm{~nm}, 350 \mathrm{~nm}, 380 \mathrm{~nm})$ the amplitudes of the ortho-normalised Ring spectra have their minimum. Thus the fit coefficient of the standard Ring spectrum directly yields the strength of the Ring effect (Wagner et al., 2009a).

For the Ring effect analysis at $430 \mathrm{~nm}$ much simpler settings than in the UV were used for two reasons: first, Ring spectral features are mainly present in a small wavelength range below $440 \mathrm{~nm}$. In addition, only few atmospheric absorbers have to be considered in that spectral range. Thus we decided to limit the spectral range to a small fitting window (426-440 nm) and to include only one atmospheric absorber: $\mathrm{NO}_{2}$. For this small spectral range, the wavelength 
Table 1. Overview on the selected parameters for the different spectral analyses.

\begin{tabular}{|c|c|c|c|c|c|}
\hline Analysis & $\begin{array}{l}\text { Wavelength } \\
\text { range (nm) }\end{array}$ & $\begin{array}{l}\text { Degree of } \\
\text { polynomial }\end{array}$ & $\begin{array}{l}\text { Reference } \\
\text { spectra }\end{array}$ & Preparation & Source \\
\hline $\begin{array}{l}\text { Ring effect } \\
335 \mathrm{~nm}\end{array}$ & $325-344$ & 4 & $\begin{array}{l}\text { standard Ring } \\
\text { cloud Ring } \\
\mathrm{NO}_{2} 220 \mathrm{~K} \\
\mathrm{O}_{3} 221 \mathrm{~K} \\
\mathrm{O}_{3} 241 \mathrm{~K} \\
\text { KAPPA_NAD } \\
\text { OBM_s_p }\end{array}$ & $\begin{array}{l}\text { convolution } \\
\text { convolution } \\
\text { convolution } \\
\text { interpolation } \\
\text { interpolation }\end{array}$ & $\begin{array}{l}\text { direct sun spectrum } \\
\text { direct sun spectrum } \\
\text { Vandaele et al (1998) } \\
\text { Bogumil et al. (2003) } \\
\text { Bogumil et al. (2003) } \\
\text { instrument keydata } \\
\text { instrument keydata }^{2}\end{array}$ \\
\hline $\begin{array}{l}\text { Ring effect } \\
350 \mathrm{~nm}\end{array}$ & $340-360$ & 3 & $\begin{array}{l}\begin{array}{l}\text { standard Ring } \\
\text { cloud Ring } \\
\text { vibrational Ring }\end{array} \\
\mathrm{NO}_{2} 220 \mathrm{~K} \\
\mathrm{HCHO} 298 \mathrm{~K} \\
\mathrm{BrO} 228 \mathrm{~K} \\
\mathrm{O}_{3} 221 \mathrm{~K} \\
\mathrm{O}_{3} 241 \mathrm{~K} \\
\mathrm{O}_{4} 296 \mathrm{~K} \\
\text { KAPPA_NAD } \\
\text { OBM_s_p }\end{array}$ & $\begin{array}{l}\text { convolution } \\
\text { convolution } \\
\text { convolution } \\
\text { convolution } \\
\text { convolution } \\
\text { interpolation } \\
\text { interpolation } \\
\text { interpolation }\end{array}$ & $\begin{array}{l}\text { direct sun spectrum } \\
\text { direct sun spectrum } \\
\text { T. Kurosu, personal } \\
\text { communication, } 2006 \\
\text { Vandaele et al. (1998) } \\
\text { Meller et al. (2000) } \\
\text { Wilmouth et al. (1999) } \\
\text { Bogumil et al. (2003) } \\
\text { Bogumil et al. (2003) } \\
\text { Greenblatt et al. (1990) } \\
\text { instrument keydata }^{2} \\
\text { instrument keydata }^{2}\end{array}$ \\
\hline $\begin{array}{l}\text { Ring effect } \\
380 \mathrm{~nm}\end{array}$ & $370-390$ & 3 & $\begin{array}{l}\begin{array}{l}\text { standard Ring } \\
\text { cloud Ring } \\
\text { vibrational Ring }\end{array} \\
\mathrm{NO}_{2} 220 \mathrm{~K} \\
\mathrm{O}_{3} 221 \mathrm{~K} \\
\mathrm{O}_{4} 296 \mathrm{~K} \\
\text { KAPPA_NAD } \\
\text { OBM_s_p }\end{array}$ & $\begin{array}{l}\text { convolution } \\
\text { convolution } \\
\text { interpolation } \\
\text { interpolation } \\
\text { interpolation }\end{array}$ & $\begin{array}{l}\text { direct sun spectrum } \\
\text { direct sun spectrum } \\
\text { T. Kurosu, personal } \\
\text { communication, } 2006 \\
\text { Vandaele et al. (1998) } \\
\text { Bogumil et al. (2003) } \\
\text { Greenblatt et al. (1990) } \\
\text { instrument keydata }^{2} \\
\text { instrument keydata }^{2}\end{array}$ \\
\hline $\begin{array}{l}\text { Ring effect } \\
430 \mathrm{~nm}\end{array}$ & $426-440$ & & $\begin{array}{l}\text { standard Ring } \\
\mathrm{NO}_{2} 220 \mathrm{~K}\end{array}$ & convolution & $\begin{array}{l}\text { direct sun spectrum } \\
\text { Vandaele et al. (1998) }\end{array}$ \\
\hline $\mathrm{O}_{4} 360 \mathrm{~nm}^{3}$ & $353-390$ & 3 & $\begin{array}{l}\text { same as Ring } \\
\text { effect } 380 \mathrm{~nm}\end{array}$ & $\begin{array}{l}\text { same as Ring } \\
\text { effect } 380 \mathrm{~nm}\end{array}$ & $\begin{array}{l}\text { same as Ring } \\
\text { effect } 380 \mathrm{~nm}\end{array}$ \\
\hline $\mathrm{O}_{2} 630 \mathrm{~nm}$ & $614-683.2$ & 3 & $\begin{array}{l}\text { standard Ring } \\
\mathrm{O}_{2} 290 \mathrm{~K} \\
\mathrm{O}_{4} 290 \mathrm{~K} \\
\mathrm{H}_{2} \mathrm{O} \\
\text { inverse } \mathrm{I}_{\mathrm{O}^{-}} \\
\text {spectrum } \\
\text { grass } \\
\text { conifers } \\
\text { deciduous } \\
\text { ZETA_NAD } \\
\text { OBM_s_p }\end{array}$ & 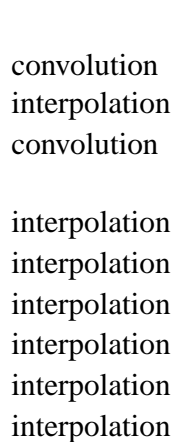 & $\begin{array}{l}\text { direct sun spectrum } \\
\text { HITRAN data base } \\
\text { Greenblatt et al. }^{4}(1990) \\
\text { HITRAN data base } \\
\text { direct sun spectrum }^{4} \\
\text { ASTER library } \\
{ }^{5} \\
\text { ASTER library } \\
\text { ASTER library } \\
\text { instrument keydata } \\
\text { intrument keydata }^{2} \\
\text { instrument keydata }^{2}\end{array}$ \\
\hline
\end{tabular}

1 see Sct. 2.2.1

2 http://www.iup.physik.uni-bremen.de/sciamachy/SCIA_CAL/rad_cal.html

${ }^{3}$ For simplicity the two band analysis $\left(360 \mathrm{~nm}\right.$ and $380 \mathrm{~nm}$ ) is referred to as $360 \mathrm{~nm}$ analysis throughout the study, the $\mathrm{O}_{4}$ cross section was scaled by 1.3 (see Wagner et al., $2009 \mathrm{~b}$; Clémer et al., 2010).

${ }^{4}$ Rothman et al. (2004)

${ }^{5}$ http://speclib.jpl.nasa.gov/ 
Table 2. Relationship between the Raman scattering probability (RSP) and other definitions of the filling-in (see also Wagner et al., 2009a)

\begin{tabular}{|c|c|c|c|c|}
\hline Study & $\begin{array}{l}\text { Instrument \& } \\
\text { spectral resolution }\end{array}$ & wavelength & $\begin{array}{l}\text { Definition of } \\
\text { filling-in }\end{array}$ & $\begin{array}{l}\text { Relationship to } \\
P_{\text {Raman }}(\lambda)\end{array}$ \\
\hline Joiner et al. (1995) & SBUV 1.1 nm & $393.37 \mathrm{~nm}$ & Filling-in factor & $=P_{\text {Raman }} \cdot 0.74$ \\
\hline Joiner et al. (2004) & $\mathrm{GOME} \sim 0.17 \mathrm{~nm}$ & $393.37 \mathrm{~nm}$ & Filling-in factor & $=P_{\text {Raman }} \cdot 2.92$ \\
\hline Joiner et al. (2006) & $\mathrm{OMI} \sim 0.50 \mathrm{~nm}$ & $393.37 \mathrm{~nm}$ & Filling-in factor & $=P_{\text {Raman }} \cdot 1.79$ \\
\hline de Beek et al. (2001) & GOME $\sim 0.17 \mathrm{~nm}$ & $393.37 \mathrm{~nm}$ & Ring DOD & $=P_{\text {Raman }} \cdot 3.02$ \\
\hline Langford et al. (2007) & Ground based $\sim 0.33 \mathrm{~nm}$ & $344.1 \mathrm{~nm}$ & Fractional filling-in & $=P_{\text {Raman }} \cdot 1.01$ \\
\hline
\end{tabular}

dependence of the amplitude of the Ring effect is small and thus only one Ring spectrum was included. These simplified settings allowed a very stable and fast algorithm. This algorithm should, however, be used only over the continents, because the Ring spectrum for vibrational Raman scattering in water was not included. Examples of the different Ring analyses are presented in Fig. 3.

The derived fit coefficient of the normalised Ring spectrum directly yields the so-called Raman scattering probability (RSP; see Wagner et al., 2009a), which describes the probability for an observed photon to have been Ramanscattered on air molecules in the atmosphere (see also Eq. 3). The advantage of using the RSP compared to other definitions for the strength of the Ring effect (see e.g. Joiner et al., 1995a,b; deBeek et al., 2001; Langford et al., 2007) is that it is independent on the specific choice of a Fraunhofer line and in particular also on the spectral resolution of the instrument. The RSP is directly proportional to the filling-in calculated from other definitions of the filling in and can be easily converted into these definitions (for details see Wagner et al., 2009a). Conversion factors for selected definitions of the filling in are given in Table 2.

Another advantage of the RSP is that it can directly be compared to the results of the radiative transfer simulations (the fit coefficient of the normalised Ring spectrum, see Sect. 3).

The uncertainty (standard deviation) of the retrieved Ring results is calculated from the fit residuals of the spectral analysis. For the Ring analyses this uncertainty is very small (typically between $1 \%$ and $2 \%$ ). As mentioned before, for SCIAMACHY observations the Ring effect analysis might by systematically affected by the polarisation sensitivity of the instrument. Thus the errors derived from the fit residuals are probably a lower limit of the actual accuracy of the SCIAMACHY Ring effect retrievals. However, for satellite instruments, which are not sensitive to polarisation (like e.g. OMI), the fit errors represent the true accuracy of the Ring retrieval. Expressed as Raman scattering probability (RSP) the accuracy of Ring effect analyses ranges between about 0.0003 for $430 \mathrm{~nm}$ and 0.001 for $335 \mathrm{~nm}$.

\subsection{2 $\mathrm{O}_{4}$ analysis}

The analysis of the $\mathrm{O}_{4}$ absorption is performed in the UV and includes two absorption bands (at $360 \mathrm{~nm}$ and $380 \mathrm{~nm}$ ). In principle, $\mathrm{O}_{4}$ absorption bands in the visible part of the spectrum could also be used (see e.g. Greenblatt et al., 1990). In this study we did not analyse further $\mathrm{O}_{4}$ bands, because at $477 \mathrm{~nm}$ the SCIAMACHY instrument suffers from strong spectral features due to its polarisation sensitivity (see Fig. 2), which interfere with the $\mathrm{O}_{4}$ analysis. At larger wavelengths $(577 \mathrm{~nm}, 630 \mathrm{~nm})$, spectral interference with strong absorptions of $\mathrm{O}_{2}, \mathrm{O}_{3}$, and $\mathrm{H}_{2} \mathrm{O}$ can lead to problems. These problems might be solved in future analyses by using satellite instruments without pronounced spectral polarisation sensitivities and improved absorption cross sections for the atmospheric $\mathrm{O}_{2}$ and $\mathrm{H}_{2} \mathrm{O}$ absorptions.

The spectral analysis yields the so-called slant column density (SCD), the trace gas concentration integrated along the atmospheric light paths. For the comparison with radiative transfer simulations, the $\mathrm{O}_{4} \mathrm{SCD}$ is divided by the vertically integrated $\mathrm{O}_{4}$ concentration (vertical column density, VCD), which is calculated from standard temperature and pressure profiles (United States Committee on Extension to the Standard Atmosphere, 1976). In our study, an $\mathrm{O}_{4} \mathrm{VCD}$ of $1.3 \times 10^{43} \mathrm{molec}^{2} / \mathrm{cm}^{5}$ was used (for the units of the $\mathrm{O}_{4}$ column density, see e.g. Greenblatt et al., 1990). The ratio between SCD and VCD yields the air mass factor (AMF):

$$
\mathrm{AMF}=\mathrm{SCD} / \mathrm{VCD}
$$

It can be directly compared to the AMF derived from the radiative transfer modelling (see Sect. 3). It should be noted that for the $\mathrm{O}_{4}$ analysis the selected wavelength range includes not only the absorption band at $360 \mathrm{~nm}$ but also the weaker absorption band at $380 \mathrm{~nm}$. This extended wavelength range was chosen to minimise fit uncertainties (which are typically on the order of 5\% to 10\%). An example for the spectral analysis is presented in Fig. 3.

For the comparison with radiative transfer simulations the choice of a more extended wavelength range leads to a slight inconsistency, because the simulations are performed for only one wavelength, $360 \mathrm{~nm}$. Although the wavelength dependency of the AMF is small (a few percent difference 
A) Ring effect $335 \mathrm{~nm}$ (fit error: 2\%)

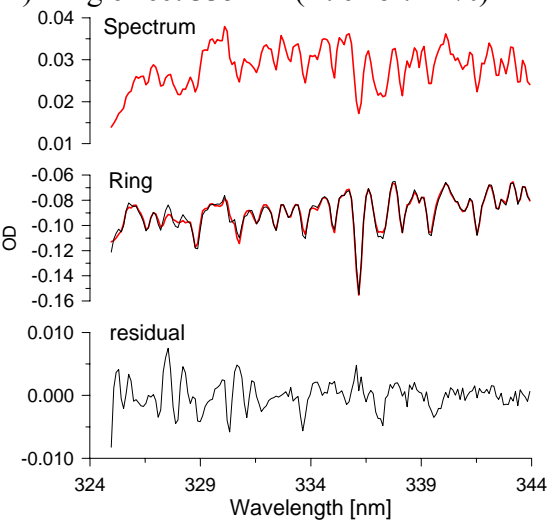

C) Ring effect $380 \mathrm{~nm}$ (fit error: 1\%) $0.08 \exists$ Spectrum

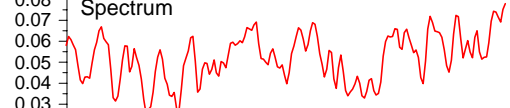
0.03 -

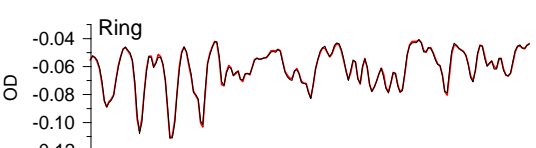

-0.12 J

0.005

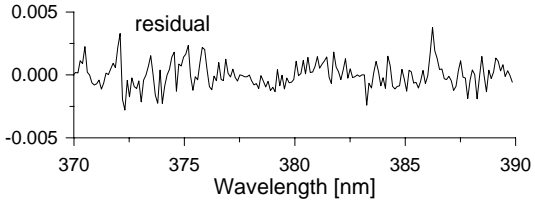

E) $\mathrm{O}_{4}$ absorption $360 \mathrm{~nm}$ (fit error: $\sim 7 \%$ )

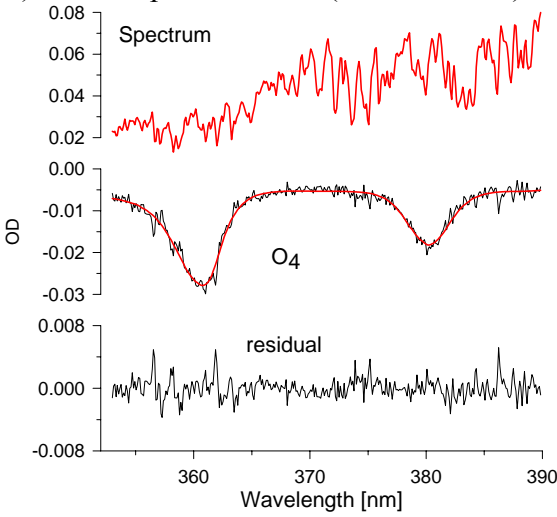

B) Ring effect $350 \mathrm{~nm}$ (fit error: 1\%)

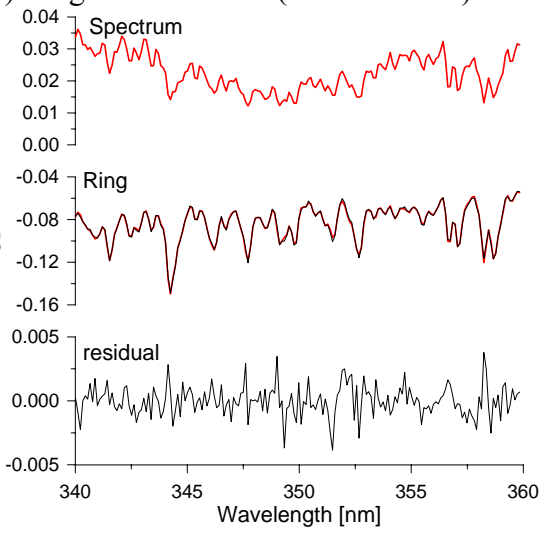

D) Ring effect $430 \mathrm{~nm}$ (fit error: $\sim 1.5 \%$ )

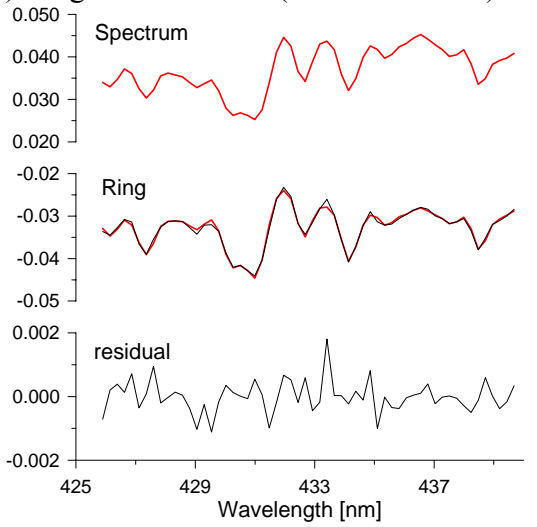

F) $\mathrm{O}_{2}$ absorption $630 \mathrm{~nm}$ (fit error: $\sim 1 \%$ )

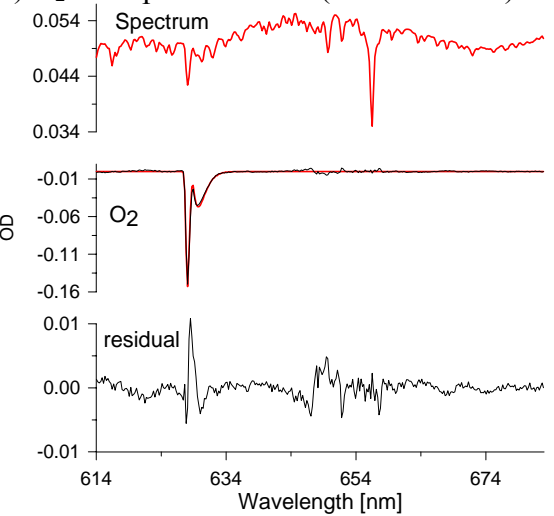

Fig. 3. Fit results of the spectral analyses of the Ring effect in different wavelength ranges (A-D) and the $\mathrm{O}_{2}$ and $\mathrm{O}_{4}$ absorptions (E, F). In each graph, the top panels show the measured raw spectra; the middle panels show the respective reference spectra (red) and the retrieved signature from the spectral analysis (black); the bottom panels show the spectral residuals.

between $360 \mathrm{~nm}$ and $380 \mathrm{~nm}$ ), no exact agreement between measurements and radiative transfer simulations can be expected. Additional discrepancies can be caused by the uncertainty of the $\mathrm{O}_{4}$ cross section and its temperature dependence (see e.g. Wagner et al., 2009b and Clémer et al., 2010).

\subsection{3 $\mathrm{O}_{2}$ analysis}

The $\mathrm{O}_{2}$ absorption is analysed at $630 \mathrm{~nm}$; details of the analysis can be found in Wagner et al. (2007). An example of the spectral analysis is shown in Fig. 3. The uncertainty of the spectral analysis is typically about $1 \%$. Like for the $\mathrm{O}_{4}$ analysis, we calculated AMFs from the measured $\mathrm{O}_{2}$ SCDs using Eq. (1). For the $\mathrm{O}_{2} \mathrm{VCD}$ a value of $4.68 \times 10^{24} \mathrm{molec} / \mathrm{cm}^{2}$ is used, calculated from pressure and temperature profiles of 
the US standard atmosphere (United States Committee on Extension to the Standard Atmosphere, 1976). Because of the limited spectral resolution of the SCIAMACHY instrument, the strong and fine-structured atmospheric $\mathrm{O}_{2}$ absorption can not be fully resolved. Thus a non-linear relationship between the measured absorption (optical depth) and the atmospheric slant column density arises, which is typically referred to as saturation, see e.g. Wagner et al. (2003). In this study we did not correct the saturation effect for the observed $\mathrm{O}_{2}$ absorptions, but instead applied a respective correction for the results of the radiative transfer simulations (see Sect. 3).

It should be noted that also the $\mathrm{O}_{2} \mathrm{~A}$ band (around $760 \mathrm{~nm}$ ) could be used for the retrieval of aerosol properties (e.g. Koppers et al., 1997; Stephens and Heidinger, 2000; Heidinger and Stephens, 2000; Boesche et al., 2008; Dubuisson et al., 2009). An important advantage of $\mathrm{O}_{2} \mathrm{~A}$ band observations is that because of the strong absorption they can in principle be analysed with high accuracy (although a rather high accuracy of about $1 \%$ is also achievable for the $\mathrm{O}_{2}$ absorption at $630 \mathrm{~nm}$, see Fig. 3). Another advantage is that depending on the absorption strength of individual lines the light observed by the satellite has "seen" different altitude layers of the atmosphere, making $\mathrm{O}_{2} \mathrm{~A}$ band measurements especially sensitive to the vertical profile (Koppers et al., 1997). However, because of the much stronger absorption compared to $630 \mathrm{~nm}$, no simple DOAS retrieval can be performed for the $\mathrm{O}_{2} \mathrm{~A}$ band. Thus we did not include an analysis of the $\mathrm{O}_{2} \mathrm{~A}$ band in this study.

It should be noted that the retrieval of information on aerosols close to the surface is mainly based on the weaker parts of the $\mathrm{O}_{2}$ A band, for which the observed light has actually penetrated into the near-surface layers of the atmosphere. To compare the potential of $\mathrm{O}_{2} \mathrm{~A}$ band observations for aerosol retrievals to the results for $\mathrm{O}_{2}$ absorptions at $630 \mathrm{~nm}$, we included radiative transfer results for the weaker parts of the $\mathrm{O}_{2} \mathrm{~A}$ band in this study (see Sect. 3).

\subsubsection{Analysis of the normalised radiance}

The SCIAMACHY observations provide spectra of the radiance $(I)$ scattered by the atmosphere and reflected by the Earth's surface and of the direct solar irradiance $(F)$. From these measurements the normalised radiance can be calculated according to the following formula:

$I_{\text {normalised }}=\frac{I \cdot \pi}{F}$

Here it should be noted that in many studies the definition of the normalised radiance also considers the effect of changing solar position (by dividing $I_{\text {normalised }}$ in Eq. 2 by the cosine of the solar zenith angle). In this study we did not apply such a correction, because we are interested in the direct dependence of the (normalised) radiance on aerosol properties (instead of the dependence of the albedo at the top of the atmosphere).

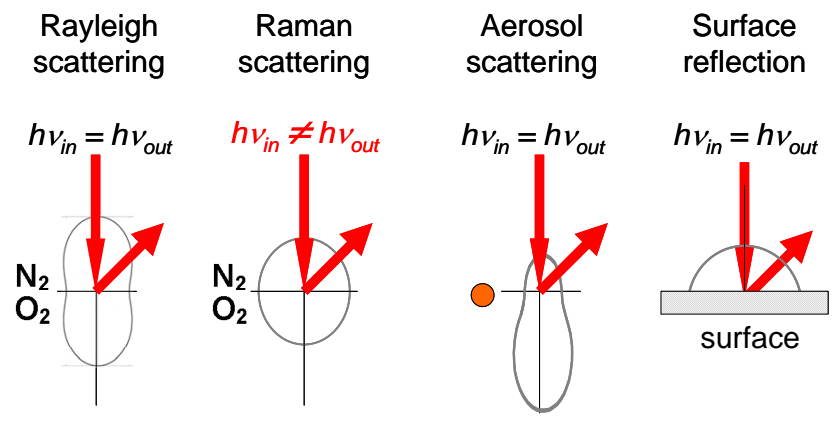

Fig. 4. Angular dependence of different types of scattering and reflection. Compared to Rayleigh scattering and aerosol scattering the angular dependence of rotational Raman scattering is weak. Thus, for a scattering angle of $90^{\circ}$ the relative contribution of Raman scattering (and thus the Ring effect) is strongest.

We extracted the normalised radiance for most of the wavelengths for which also the Ring effect and the $\mathrm{O}_{2}$ absorption were analysed: $335 \mathrm{~nm}, 350 \mathrm{~nm}, 380 \mathrm{~nm}, 430 \mathrm{~nm}$, $630 \mathrm{~nm}$. For the extraction of the normalised radiance from SCIAMACHY (including the correction of the polarisation dependence of the instrument), the so-called Müller-matrix approach was used (Lichtenberg et al., 2006).

\section{Radiative transfer simulations}

The radiative transfer simulations are performed using the full spherical Monte-Carlo radiative transfer model McArtim (Deutschmann, 2009; Deutschmann and Wagner, 2008). The model allows the simulation of ensembles of individual photon trajectories for a given atmospheric situation. From these trajectories the probability of the modelled photons for certain interactions with atmospheric constituents or with the Earth's surface are determined. The scattering events are modelled individually, according to their respective scattering cross sections and phase functions (see Fig. 4). Interaction with the Earth's surface is treated as a Lambertian reflection for a specified ground albedo. In addition to elastic processes (the reflection at the surface, Rayleigh scattering at molecules, and scattering on aerosol and cloud particles), also rotational Raman scattering events are simulated, allowing to model the Ring effect with McArtim (Wagner et al., 2009a). The simulation results of McArtim were in detail compared to other studies (for radiances and AMFs, see Wagner et al., 2007; for the Ring effect, see Wagner et al., 2009a), and good agreement was found.

McArtim is a scalar model, which does not explicitly include the effects of polarisation. Thus, especially for cases with few (more than one) Rayleigh-scattering events, systematic errors of the simulated radiance of up to about $10 \%$ can occur for specific viewing geometries (Mishchenko et al., 1994; Landgraf et al., 2004; Spurr et al., 2008). Such cases particularly include cloud-free observations in the UV, 
which are relevant for this study. Fortunately, as was shown by Landgraf et al. (2004) (see also discussion in Spurr et al., 2008), that the strength of the filling-in is only weakly affected by the neglect of polarisation, because the phase function for Raman scattering depends only weakly on polarisation, and because in the UV a Raman-scattered photon has typically also undergone Rayleigh-scattering events before or after the Raman scattering event. Thus, systematic errors of the elastic and inelastic contributions of the observed radiance are similar and mainly cancel out when the ratio (i.e. the filling in) is calculated.

Our model differs from the model used by Landgraf et al. (2004): instead of the Raman scattered radiance, the probability of an observed photon to have undergone Raman scattering is simulated. Nevertheless, the same arguments hold also for our model: the probability for Rayleigh scattering and that for Raman scattering are affected in the same way by the neglect of polarisation; thus for the calculation of the Raman scattering probability these errors almost cancel out. This rationale is supported by the good quantitative agreement of our model results with results of other models (see Wagner et al., 2009a).

Various model runs are performed for different atmospheric scenarios (different aerosol loads and optical properties) and viewing geometries (varying solar zenith angles, viewing angles and relative azimuth angles). The surface albedo was set to $5 \%$ for the UV and blue spectral range and to $10 \%$ and $20 \%$ for $630 \mathrm{~nm}$ and $758 \mathrm{~nm}$, respectively (see e.g. Herman and Celarier et al., 1997; Koelemeijer et al., 2003; Kleipool et al., 2008).

Note that no specific aerosol models were used in our study to describe the aerosol properties and especially their wavelength dependencies. Instead we simply varied the aerosol optical properties separately for each wavelength: the single scattering albedo (SSA), asymmetry parameter ( $g$, using a Henyey-Greenstein approximation of the aerosol phase function; Henyey and Greenstein, 1941), and vertical profiles of the aerosol extinction. In this way the relationship between these optical properties and the measured quantities can be directly investigated. In cases where simulation results are directly compared to observations, the wavelength dependence of the aerosol optical depth (lower values at larger wavelengths) is taken into consideration.

As described in detail in Sect. 4.7, the Ring effect, and the $\mathrm{O}_{2}$ absorption depend only relatively weakly on the asymmetry parameter (compared to the dependence on other aerosol properties). Thus in most cases, we used a fixed value for $g$ of 0.68 (see e.g. Dubovik et al., 2002). Nevertheless, especially for the radiance and the $\mathrm{O}_{4}$ absorptions, part of the differences between observations and model simulations might be caused by deviations of the true $g$ from the assumed value of 0.68 . The sensitivity of the observed quantities on the SSA and $g$ are investigated in Sects. 4.6 and 4.7.

From the model simulations, the observed normalised radiances, the AMFs for $\mathrm{O}_{4}$ and $\mathrm{O}_{2}$ (see Eq. 1), and also the
Raman scattering probability (RSP) are obtained (see also Sect. 2.2.1):

$\mathrm{RSP}=\frac{N_{\text {Raman }}}{N_{\text {total }}}$

Here $N_{\text {Raman }}$ describes the number of simulated photons which have undergone at least one rotational Raman scattering event and and $N_{\text {total }}$ the total number of simulated photons.

Note that for simplicity, the $\mathrm{O}_{2}$ AMFs were modelled assuming that $\mathrm{O}_{2}$ behaves like a weak atmospheric absorber (optical depth $<<1$ ), instead of modelling the actual strong and fine-structured atmospheric $\mathrm{O}_{2}$ absorption. To correct for these assumptions, a subsequent saturation correction was applied to the simulated $\mathrm{O}_{2}$ AMFs for $630 \mathrm{~nm}$ (see Wagner et al., 2003 and Grzegorski, 2009), before being compared to the measured $\mathrm{O}_{2} \mathrm{AMF}$.

\section{Sensitivity studies}

In this section, we explore the general dependencies of the Ring effect, the $\mathrm{O}_{2}$ and $\mathrm{O}_{4}$ absorptions, and the normalised radiances on the observation geometry (solar zenith angle and viewing angle) and aerosol properties (AOD, SSA, $g$, and layer height).

\subsection{Dependence on the solar zenith angle}

The interpretation of aerosol effects on satellite observations depends critically on the correct consideration of the observational geometry, especially the dependencies on the solar zenith angle (SZA) and the viewing angle of the instrument. In this sub-section the dependence on SZA is investigated.

In Figs. 5 and 6 observations of the Ring effect, the $\mathrm{O}_{4}$ and $\mathrm{O}_{2}$ absorption, and the normalised radiance over Beijing for cloud-free conditions are shown as a function of the time of year. In addition, the modelled SZA dependencies for aerosol-free conditions are shown.

In general, the observed SZA dependence is well described by the model. But also the influence of aerosols can be seen by comparing measured and modelled results: for the observed Ring effect and $\mathrm{O}_{2}$ absorptions, most values are smaller than the model results (where aerosol-free conditions are assumed). This indicates the importance of the shielding effect on the measured quantities. For the $\mathrm{O}_{4}$ absorptions also many observations with higher values compared to the model simulations are found. Here, the albedo effect becomes important (see Sect. 1). For the observed normalised radiances, as expected, in most of the observations the radiances are higher than the model results, which can be explained by the additional scattering by aerosol particles. In Sect. 4.4 we will use the simulated values (for aerosol-free conditions) to remove the SZA dependence from the observations of the Ring effect and $\mathrm{O}_{4}$ and $\mathrm{O}_{2}$ absorptions. 

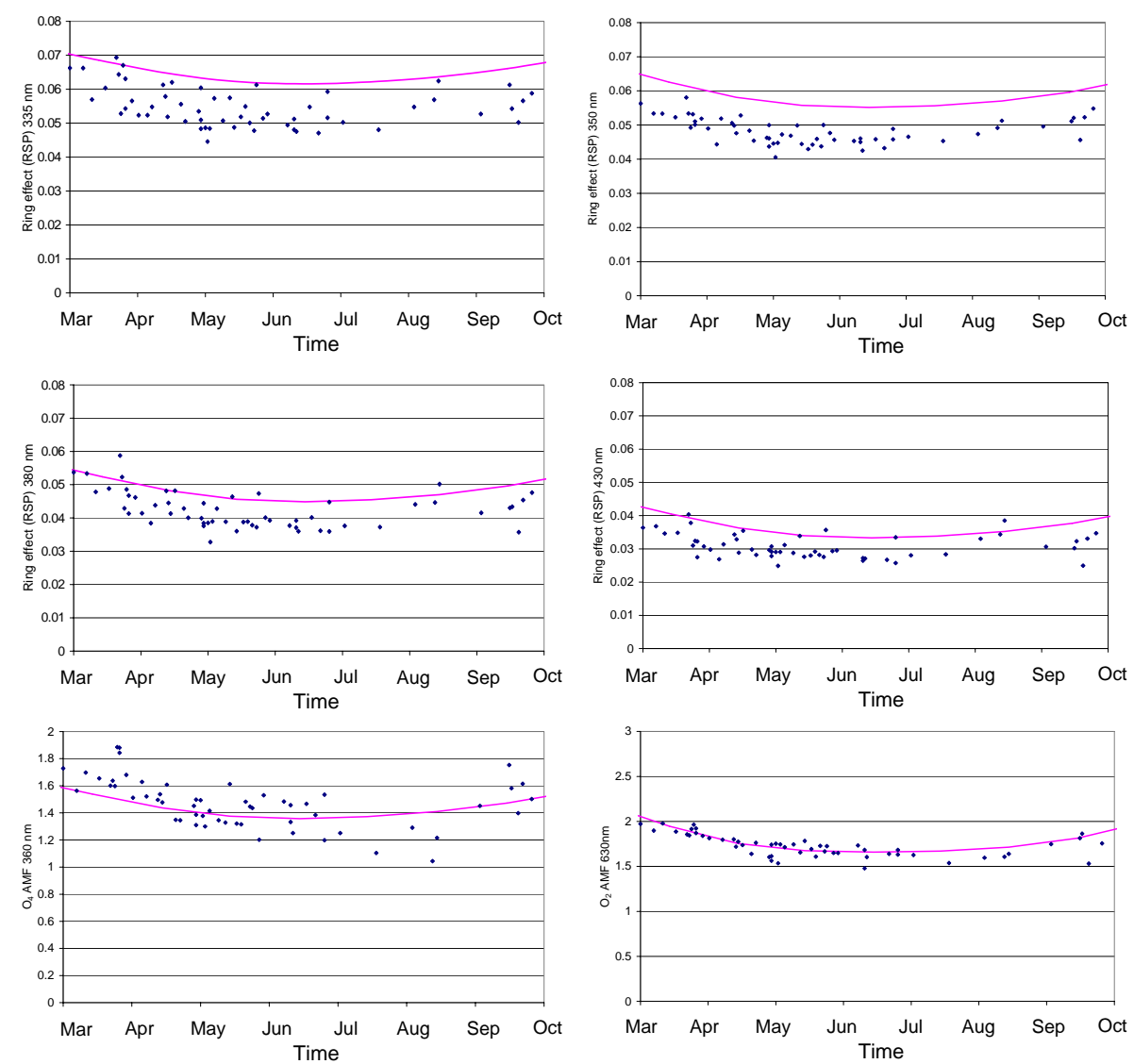

Fig. 5. Seasonal variation (March to October) of the Ring effect and $\mathrm{O}_{2}$ and $\mathrm{O}_{4}$ absorption over Beijing. The measurements include only cloud-free observations. The magenta lines represent the result of radiative transfer simulations (see Sect. 3) for aerosol-free conditions. For $630 \mathrm{~nm}$ the surface albedo was set to $10 \%$; for all other wavelengths it was set to $5 \%$.

We also simulated the SZA dependence of the Ring effect and the $\mathrm{O}_{2}$ and $\mathrm{O}_{4}$ absorption for various assumed aerosol optical properties (see Fig. A1 of the Appendix). For these quantities, a systematic increase with increasing SZA is found for all wavelengths, which is a result of two effects:

a. Effect of scattering phase function (see Fig. 4)

For singly scattered photons, the scattering angle is determined by the viewing angle and the SZA. For a nadir looking instrument the scattering angle is given by $180^{\circ}$-SZA. Because of the different phase functions for Raman scattering and elastic scattering processes (see Fig. 4, also Kattawar et al., 1981) the probability for Raman scattering (and thus the strength of he Ring effect) increases towards high SZA. For the absorptions of $\mathrm{O}_{4}$ and $\mathrm{O}_{2}$, the effect of scattering angle is of minor importance.

b. Effect of atmospheric path length

The atmospheric light path lengths also increase with increasing SZA, which leads to an increased probability for molecular scattering and absorption. The light path effect is especially important for the $\mathrm{O}_{2}$ and $\mathrm{O}_{4}$ absorptions.

It is interesting to note that the relative dependence of the Ring effect and the $\mathrm{O}_{2}$ and $\mathrm{O}_{4}$ absorptions on the SZA is similar for all chosen aerosol scenarios. This behaviour allows a rather simple correction of the SZA dependence (see Sect. 4.4).

\subsection{Dependence on the viewing angle}

In addition to the SZA, the viewing angle of the instrument can also have an important effect on the observed quantities. Note that in this study the viewing angle is defined with respect to the horizon: nadir observations are indicated by a viewing angle of $-90^{\circ}$; viewing angles $>-90^{\circ}$ indicate viewing angles towards the east and viewing angles $<-90^{\circ}$ indicate viewing angles towards the west.

We investigated the viewing angle dependencies using observational and simulation results. The search for well-suited satellite observations turned out to be difficult, because for an unambiguous interpretation of the measurements several conditions have to be fulfilled: 

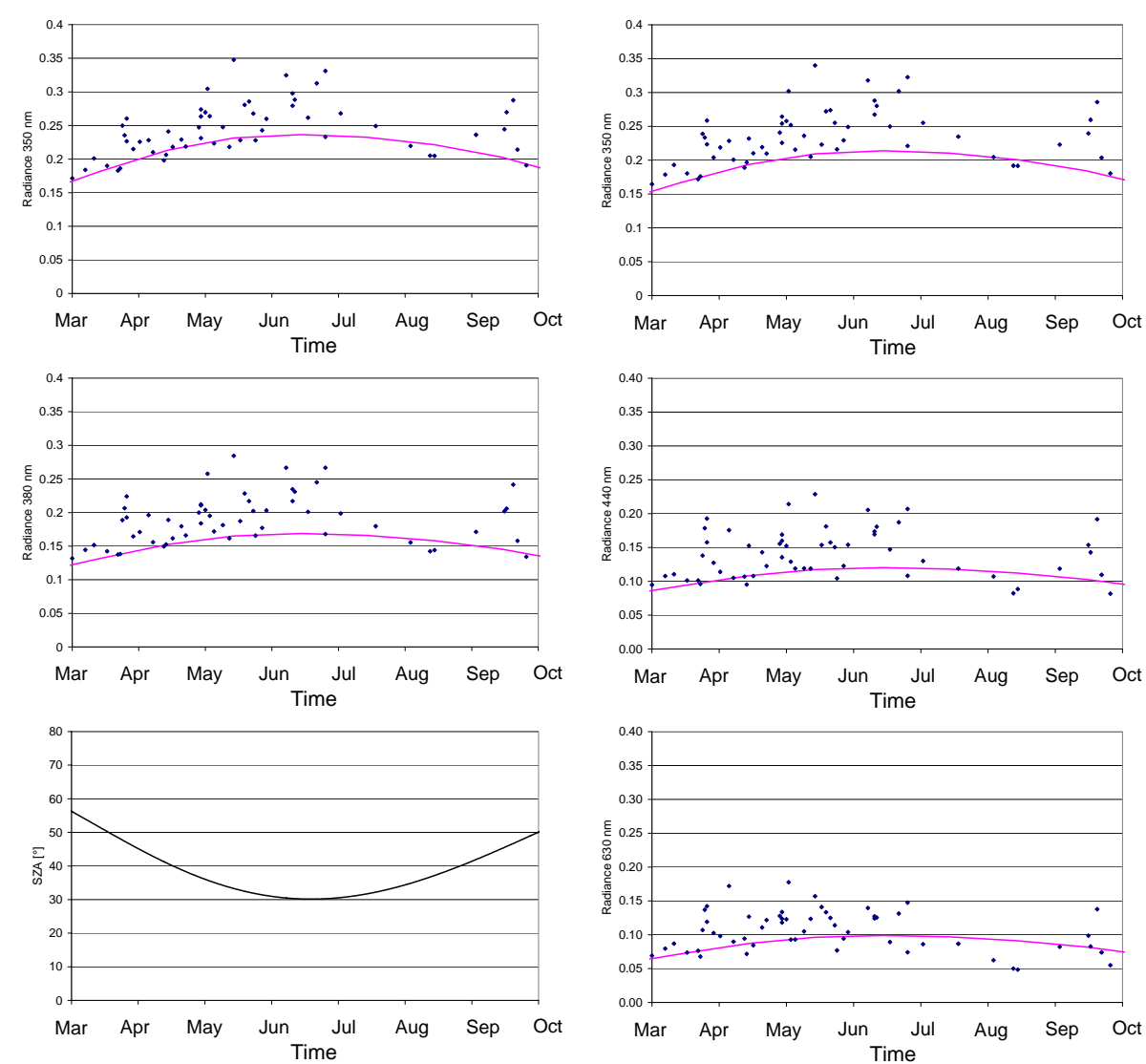

Fig. 6. Seasonal variation (March to October) of the normalised radiances over Beijing. The measurements include only cloud-free observations. The magenta lines represent the result of radiative transfer simulations (see Sect. 3) for aerosol-free conditions. Also shown is the seasonal variation of the SZA (lower left panel). For $630 \mathrm{~nm}$ the surface albedo was set to $10 \%$; for all other wavelengths it was set to $5 \%$.

- Cloud contamination has to be avoided, since usually the effects of clouds are much larger than those of aerosols.

- Areas with high surface elevation should be avoided, because the Ring effect and $\mathrm{O}_{2}$ and $\mathrm{O}_{4}$ absorptions also depend on the terrain height.

- Scenes with high AOD should be avoided to minimise uncertainties of radiative transfer simulations caused by imperfect knowledge of the aerosol properties.

- Observations over oceans should be avoided, because sun glint also has a strong effect on the observed quantities; also water absorption and vibrational Raman scattering might complicate the interpretation of the results.

Based on these conditions we identified a few well suited SCIAMACHY observations, of which one example, in Eastern Europe on 17 September 2006, is shown in Fig. 7. Also displayed are the locations of the SCIAMACHY observations for which the viewing angle dependence is investigated (red box). For these observations the sky was completely cloud-free, and also the aerosol load was rather low: from

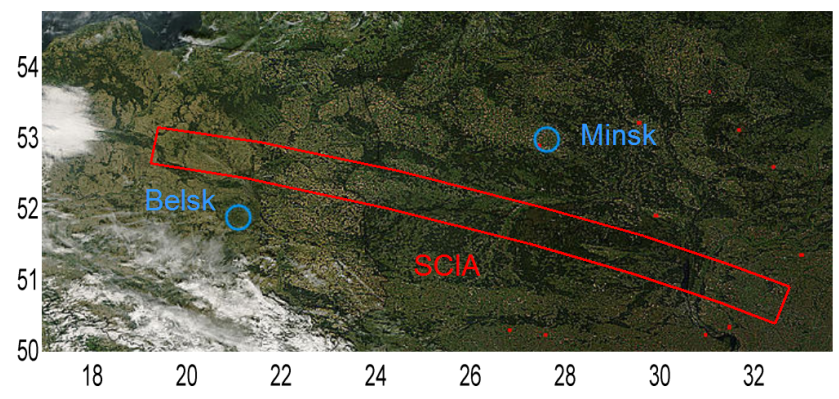

Fig. 7. MODIS RGB image over Eastern Europe on 17 September 2006. On this day, the sky was almost cloud-free and very low AOD (below 0.1 in the UV) were measured by an AERONET station in Minsk (marked with a blue circle). The red lines indicate the location of two west-east scanning sequences of the SCIAMACHY instrument on that day. Red dots in the figure indicate MODIS fire counts, but they are ignored here. The observed Ring effect, $\mathrm{O}_{4}$ and $\mathrm{O}_{2}$ absorption, as well as the normalised radiances for these measurements are shown in Figs. 8 and 9. 

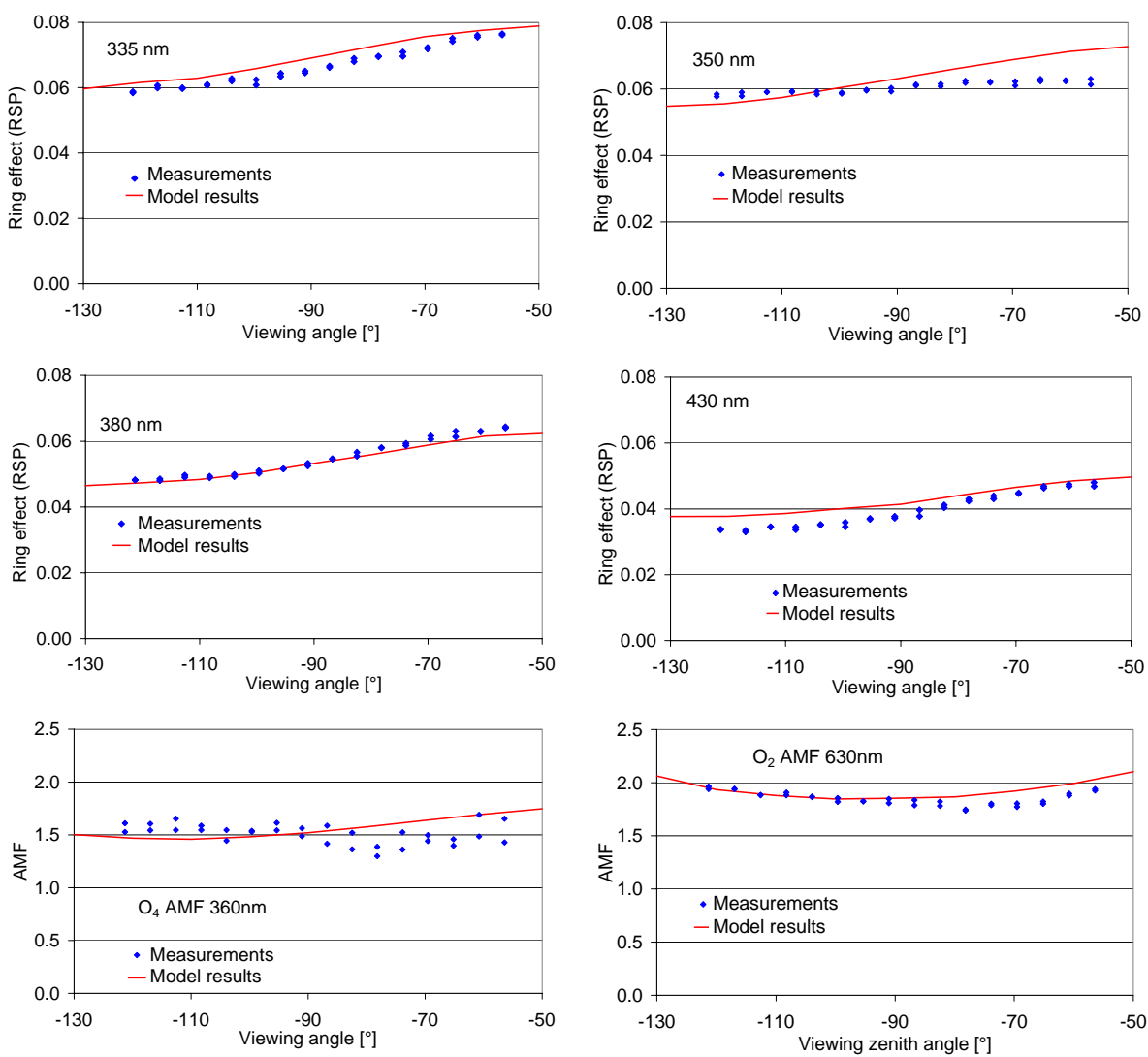

Fig. 8. Observed (blue dots) and modelled dependency of the Ring effect and the $\mathrm{O}_{4}$ and $\mathrm{O}_{2}$ absorption on the viewing angle for selected cloud-free observations (results of two consecutive SCIAMACHY scans) over Eastern Europe (17 September 2006, see Fig. 7). The deviations of the measured $\mathrm{O}_{4}$ and $\mathrm{O}_{2}$ absorptions from the simulated values are probably related to variations of the surface albedo. For the radiative transfer calculations the following parameters were assumed: surface albedo: $3 \%$, the aerosol layer: $0-1 \mathrm{~km}$; aerosol SSA: 0.95 ; $g$ : 0.68 , AOD: $0.05(630 \mathrm{~nm})$ and 0.1 (all other wavelengths). A viewing angle of $-90^{\circ}$ indicates nadir viewing geometry. Note that the simulated $\mathrm{O}_{2} \mathrm{AMFs}$ were corrected for the saturation effect (see Sect. 3).

AERONET observations at Minsk AOD of 0.1 and 0.05 in the UV and red spectral range were observed, respectively. These values for AOD were used in the radiative transfer simulations. Red dots in Fig. 7 indicate fire counts by the MODIS instrument, but these are not relevant to our study.

Figure 8 shows the results of the SCIAMACHY observations of the Ring effect and the $\mathrm{O}_{4}$ and $\mathrm{O}_{2}$ absorption, together with results of the radiative transfer simulations. For these simulations, the SZA and viewing geometry corresponding to the SCIAMACHY observations were used.

As expected, the Ring effect observations show a systematic dependence on the viewing angle, which in general is in good agreement with the radiative transfer simulations. However, one exception is found for the Ring effect observations at $350 \mathrm{~nm}$, which depend only slightly on the viewing angle. This finding is not yet fully understood, but is probably an artefact related to the strong polarisation sensitivity of the SCIAMACHY instrument around $350 \mathrm{~nm}$ (see Fig. 2).

Also for the $\mathrm{O}_{2}$ and $\mathrm{O}_{4}$ absorptions an overall good agreement between observations and modelling results is found.
The differences for the eastern pixels of the SCIAMACHY swath are probably caused by the very low values of the surface albedo at these locations (see Fig. 7). Additional uncertainties might be caused by the fact that the bi-directional reflection function over vegetation is probably not well described by a Lambertian reflector.

Figure 9 shows the observed normalised radiances, together with results of the radiative transfer simulations. While the general dependence on the viewing angle is well reproduced, also a systematic overestimation of the observed radiance by the model simulations towards short wavelengths is obvious. The reason of this overestimation is not completely clear. One reason might again be the influence of the strong polarisation sensitivity of the SCIAMACHY instrument in the UV spectral range (see Fig. 2). In addition, in cases with low surface albedo and low AOD, the deficiencies of a scalar radiative transfer model like $\mathrm{McAr}$ tim to describe the true atmospheric radiation field might become relatively large (see e.g. Mishchenko et al., 1994; Landgraf et al., 2004). Finally, the assumed low surface 

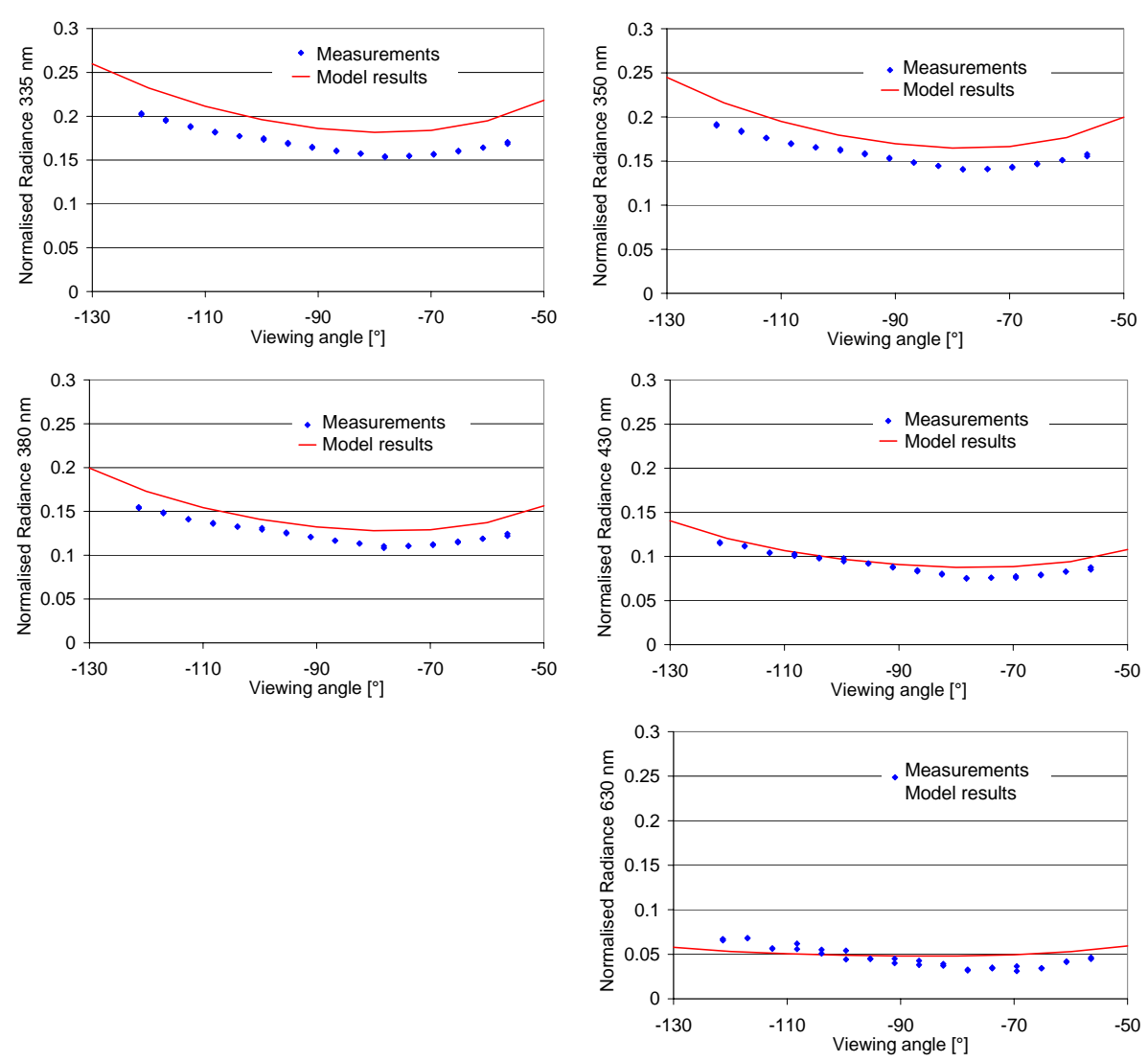

Fig. 9. Observed (blue dots) and modelled dependency of the normalised radiance on the viewing angle for selected cloud-free observations (results of two consecutive SCIA scans) over Eastern Europe (17 September 2006, see Fig. 7). For the radiative transfer calculations the following parameters were assumed: surface albedo: $3 \%$, the aerosol layer: $0-1 \mathrm{~km}$; aerosol SSA: 0.95; $g$ : 0.68, AOD: 0.05 (630 nm) and 0.1 (all other wavelengths). A viewing angle of $-90^{\circ}$ indicates nadir viewing geometry.

albedo (3\%) for the simulations might be still too high: like for the $\mathrm{O}_{4}$ and $\mathrm{O}_{2}$ absorptions, especially low values in the eastern part of the swath are found, indicating a very low surface albedo. It is interesting to note that from the MODIS observations over this region even small, negative AOD are retrieved on that day (MODIS GIOVANNI product from the NASA Goddard space flight center web site: http://aeronet.gsfc.nasa.gov/cgi-bin/bamgomas_interactive).

In addition to this case study, we investigated the viewing angle dependence of the observed quantities in a more systematic way using radiative transfer simulations for various assumed aerosol properties. The results are presented in detail in Figs. A2 and A3 of the Appendix. One important finding is that unlike for the SZA dependence, very different dependencies are found for the various quantities. They also differ in strength and direction for different aerosol properties.

\subsection{Dependence on the surface albedo}

Figure 10 shows the dependence of the Ring effect, the $\mathrm{O}_{2}$ and $\mathrm{O}_{4}$ absorptions and the normalised radiance on the surface albedo. For the Ring effect and the gas absorptions quite different dependencies are found. For low albedo (below about 0.2 to 0.5 , depending on wavelength) the strength of the Ring effect decreases with increasing surface albedo. For larger albedo values, the Ring effect increases; the strongest increase is found for the smallest wavelengths. These findings can be explained by the dependence of the probability for multiple Rayleigh scattering on the surface albedo. For low surface albedo, an increase of the surface albedo has a relatively small effect on the probability for multiple scattering, but a relatively large effect on the fraction of observed photons which have been (elastically) reflected from the earth's surface. Thus for low albedo the probability of the observed photons having undergone a Raman scattering event decreases with increasing surface albedo.

For larger values of the surface albedo, the increase of the probability for multiple Rayleigh scattering (and thus also the probability for Raman scattering) with increasing surface albedo becomes the dominant effect. Since the probability for Rayleigh scattering increases towards small wavelengths, the effect of the surface albedo on the probability for multiple Rayleigh scattering is largest for small wavelengths. 

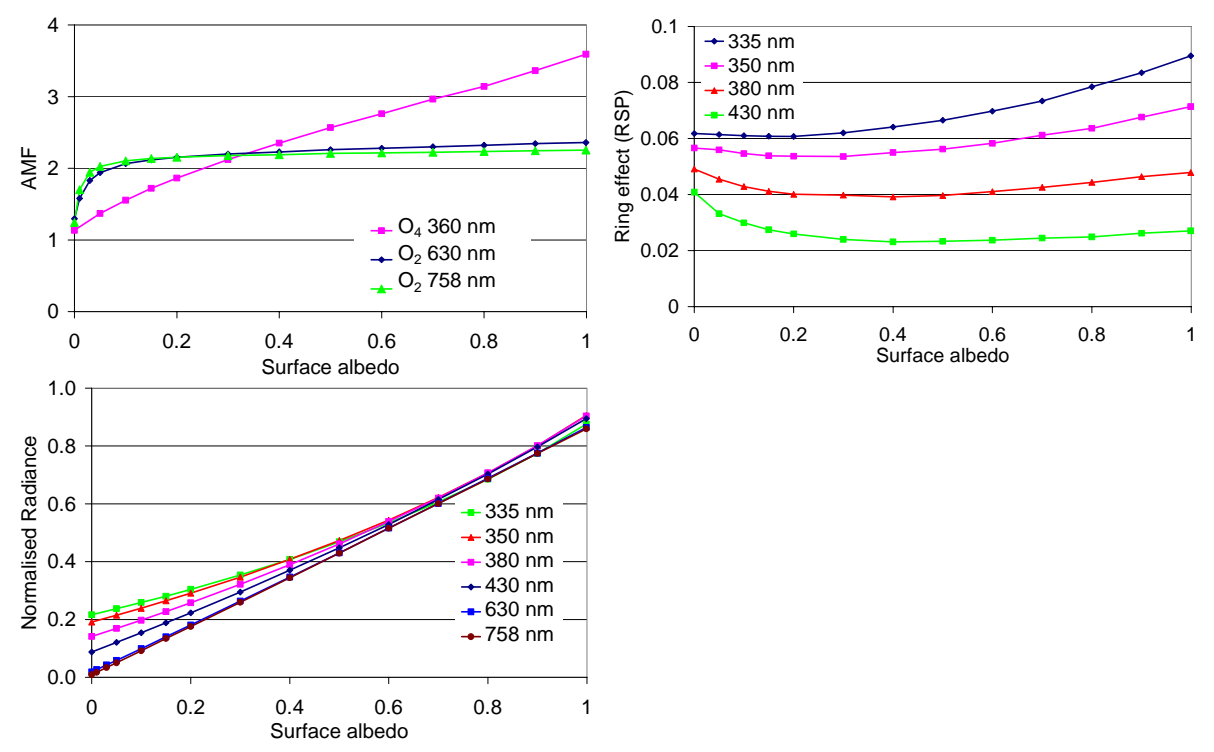

Fig. 10. Dependence of the Ring effect, the $\mathrm{O}_{2}$ and $\mathrm{O}_{4}$ absorption and the normalised radiance on the surface albedo. The calculations are performed for SZA of $30^{\circ}$ and a viewing angle of $-90^{\circ}$ (nadir geometry) and no aerosols present.

For small wavelengths even the maximum Raman scattering probability is found for a surface albedo of 1 . Also the transition from decrease to increase of the Raman scattering probability with increasing surface albedo occurs at smaller albedo values.

Note that for the Ring effect retrievals in the UV and blue spectral range, usually the surface albedo is small (except over snow and ice). Thus an increase of the surface albedo (or the albedo effect of aerosols) will usually lead to a decrease of the Ring effect.

For the $\mathrm{O}_{2}$ and $\mathrm{O}_{4}$ absorptions a systematically different behaviour is found. For all wavelengths a systematic increase with increasing surface albedo is observed. For the $\mathrm{O}_{4}$ absorption at $360 \mathrm{~nm}$ this increase is almost linear with increasing surface albedo. For the $\mathrm{O}_{2}$ absorptions at longer wavelengths, a strong increase is found for small albedo (below about $10 \%$ ) but for larger albedo only a slight further increase is found. These differences are caused by the strong wavelength dependence of Rayleigh scattering.

The difference of the dependencies of the Ring effect and the $\mathrm{O}_{2}$ and $\mathrm{O}_{4}$ absorptions on surface albedo is a very interesting finding and indicates a fundamental advantage of Ring effect observations for the retrieval of aerosol (and cloud) properties. For observations of the $\mathrm{O}_{2}$ and $\mathrm{O}_{4}$ absorptions the shielding effect and the albedo effect of aerosols have different signs and thus can partly cancel each other, leading to an ambiguity in the interpretation of these observations. In contrast, for Ring effect observations, both the shielding effect and the albedo effect typically lead to a decrease of the strength of the Ring effect (with the strongest decreasing albedo effect at small wavelengths).
Besides the general albedo effect on observations of the Ring effect and the $\mathrm{O}_{2}$ and $\mathrm{O}_{4}$ absorptions, interaction of the photons with the earth's surface can have more subtle effects on the retrieved quantities. For example, in the red spectral range, reflection by vegetation causes spectral structures in the range of a few nanometers which can interfere with atmospheric absorption structures (e.g. the $\mathrm{O}_{4}$ absorption band at $630 \mathrm{~nm}$; see Wagner et al., 2007). Fortunately, the $\mathrm{O}_{2}$ absorption at the same wavelength is almost not affected by these spectral structures.

A different kind of spectral interference can occur for observations over oceans. Especially in regions with very clear waters, vibrational Raman scattering affects the observed radiances (Vasilkov et al., 2002; Vountas et al., 2003). Fortunately, as was shown by Vountas et al. (2003), the spectral signatures of rotational Raman scattering on air molecules and of vibrational Raman scattering on water molecules show important differences. Thus both effects can in general well be distinguished in the spectral analysis. Nevertheless, some systematic effects might remain over clear oceanic regions, especially in cases of low signal to noise. However, effects of vibrational Raman scattering in water are not important for this study, because only observations over land are considered.

Finally the effect of temporally changing surface albedo has to be considered. In the UV and blue spectral range, the albedo is typically low (a few percent) and varies only weakly for different surface materials (exceptions are snow and ice, or sun glint over the oceans). In contrast, at longer wavelengths, the dependence of the albedo on surface properties is much larger and also the seasonal variation of biological activity can have a strong effect: for observations 
at $630 \mathrm{~nm}$, the albedo over vegetation is typically lower than over most other surfaces; at $760 \mathrm{~nm}$ it is typically higher than over most other surfaces. These dependencies complicate the interpretation of observations at these wavelengths. Also the albedo values of $10 \%$ and $20 \%$ used in the radiative transfer simulations for the wavelengths at $630 \mathrm{~nm}$ and $758 \mathrm{~nm}$, respectively, might differ substantially from the true albedos for these wavelengths. This should be taken into consideration for the interpretation of comparisons between measurements and observations.

\subsection{Dependence on aerosol optical depth}

In this section the dependence of the Ring effect, the $\mathrm{O}_{2}$ and $\mathrm{O}_{4}$ absorption and the normalised radiance on the AOD is investigated. For that purpose, SCIAMACHY observations over Beijing were selected. There, often high AOD are found, which allows the study of the effect of aerosols over a large range of AOD. For the characterisation of the AOD we use AERONET data from the station "Beijing" $\left(39.97^{\circ} \mathrm{N}\right.$, $116.37^{\circ} \mathrm{S}$, http://aeronet.gsfc.nasa.gov/new_web/index.html; see also Holben et al., 2001). This station provides the best temporal coverage over the selected period from 2004 to 2008. From the AERONET measurements the average AOD during one hour around the time of the SCIAMACHY overpass are calculated. The AOD at $440 \mathrm{~nm}$ and $675 \mathrm{~nm}$ was directly measured, whereas the AOD at $350 \mathrm{~nm}$ was calculated from the other wavelengths based on the Ångström coefficient retrieved for the longer wavelengths. Note that this interpolation can be subject to relatively large uncertainties (e.g. Krotkov et al., 2005). Only measurements of the AOD, for which the standard deviation during the one hour interval was less than 0.3 (at $440 \mathrm{~nm}$ ) were considered.

The satellite observations were selected according to the following criteria:

- To avoid any influence of bright surfaces due to snow or ice we selected SCIAMACHY observations only for the period from March to September.

- We ensured that the observed scenes were cloudfree from visible inspection of true color images from almost simultaneous observations (time difference 0.5 to $1 \mathrm{~h}$ ) of the MODIS instrument (MODIS on TERRA, images obtained from NASA/GSFC, MODIS Rapid Response, http://aeronet.gsfc.nasa.gov/cgi-bin/ bamgomas_interactive). If in the MODIS images any clouds or cloud fragments were observed at the location of the SCIAMACHY observations, these observation was classified as cloud-contaminated.

- Only SCIAMACHY measurements with the centre of the ground pixel within $\pm 0.15^{\circ}$ latitude and $\pm 0.30^{\circ}$ longitude around the AERONET station were considered.
In total for the selected period (2004-2008) about 55 pairs of AERONET/SCIAMACHY observations over Beijing fulfilled the selection criteria.

Before comparing the satellite and ground-based data, the effects of varying SZA and viewing geometry have to be considered. The SZA dependence is corrected by simply dividing the observational data by the model results (simulated for aerosol-free scenario) for the respective SZA (see Figs. 5 and 6). For the viewing angle dependence, no such procedure can be performed, because the viewing angle dependence varies systematically with aerosol properties (see Figs. A2 and A3 in the Appendix). Thus we decided to consider only SCIAMACHY observations for the western and centre part of the swath (viewing angles $<-81^{\circ}$ ), for which the viewing angle dependence is relatively small (Fig. A2 in the Appendix). After applying this additional criterion, 37 pairs of AERONET/SCIAMACHY observations were left. Finally, the observations are also corrected for a linear long-term trend (the results of a regression line fitted for the period 2004-2008 were subtracted).

It should be noted that in order to minimise computational effort, the AERONET AOD was not taken at exactly the same wavelength as the SCIAMACHY observations. For the observations of the Ring effect and the $\mathrm{O}_{4}$ absorption in the UV, the AOD at $350 \mathrm{~nm}$ was chosen, whereas for the Ring effect observation at $430 \mathrm{~nm}$ and the $\mathrm{O}_{2}$ absorption at $630 \mathrm{~nm}$, the $\mathrm{AOD}$ at $440 \mathrm{~nm}$ and $675 \mathrm{~nm}$ were taken, respectively. For the comparison to the model simulations, this choice of wavelengths has low impact.

In Fig. 11 (right) the correlation analysis for the observed normalised radiance versus the AOD from the AERONET station is shown. In the left part the results of the radiative transfer simulations are shown. To allow a direct comparison between observations and model simulations, also the radiative transfer results were normalised with respect to the values for aerosol-free scenarios (the radiative transfer results without normalisation are shown in Figs. A4 and A5 in the Appendix). As expected, increasing normalised radiances are found for increasing AOD. The strongest (relative) increase occurs at large wavelengths because there the influence of molecular scattering is much weaker due to the strong wavelength dependence of Rayleigh-scattering. From the comparison between observations and simulations we conclude that the aerosol over Beijing is typically weakly absorbing with an SSA of about 0.9 in the UV and about 0.95 at $630 \mathrm{~nm}$.

The correlation analyses of the observations of the Ring effect and the $\mathrm{O}_{4}$ and $\mathrm{O}_{2}$ absorptions versus the AOD from the AERONET station are shown in the right column of Fig. 12. In the left column of Fig. 12, the respective (normalised) simulation results are presented.

For the Ring effect observations, a negative dependence on the AOD is found for all wavelengths; the strength of this dependence increases towards larger wavelengths. A similar tendency is also found in the model simulations. However, 

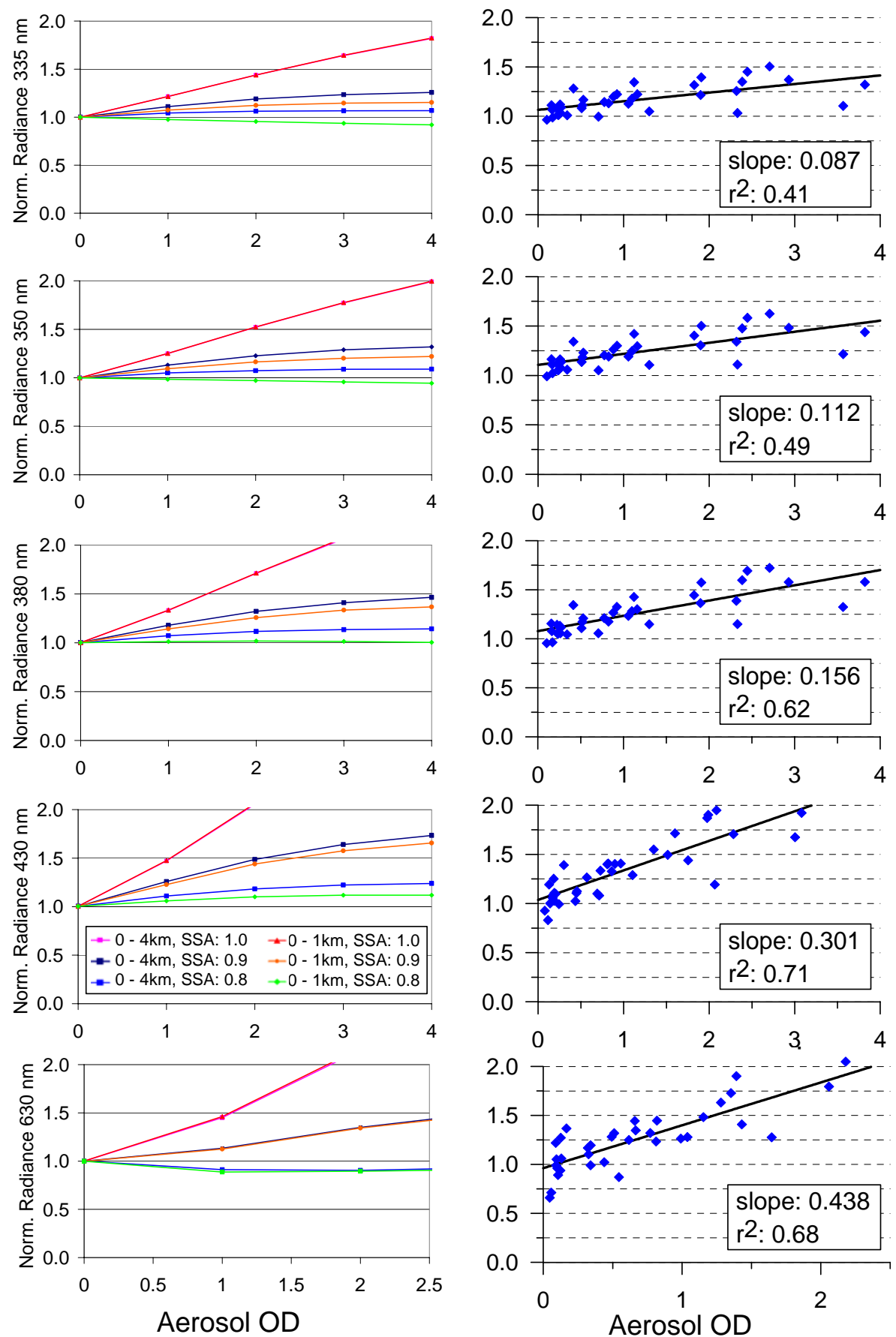

Fig. 11. Observed (right) and simulated (left) dependence of the normalised radiance on the AOD. The data are normalised to the values modelled for an AOD of 0 (see text). The calculations are performed for SZA of $30^{\circ}$ and a viewing angle of $-90^{\circ}$ (nadir). The aerosol asymmetry parameter was assumed to be 0.68 . For $630 \mathrm{~nm}$ the surface albedo was set to $10 \%$; for all other wavelengths it was set to $5 \%$.

the slope of the modelled dependencies strongly depends on the varied aerosol properties, single scattering albedo and layer height. For short wavelengths, an increase of the Ring effect is even found for purely scattering aerosols at low altitude. In contrast, for large wavelengths a decrease of the Ring effect is found for all assumed aerosol scenarios.
The comparison of observations and simulations again indicates that the aerosol over Beijing is typically weakly absorbing $(\mathrm{SSA} \approx 0.9$ ). However, it should be noted that no exact agreement is expected because the simulations were performed for fixed viewing geometry (SZA: $30^{\circ}$, viewing angle: $-90^{\circ}$ - nadir), while the satellite instrument's observation geometry varies with season. 

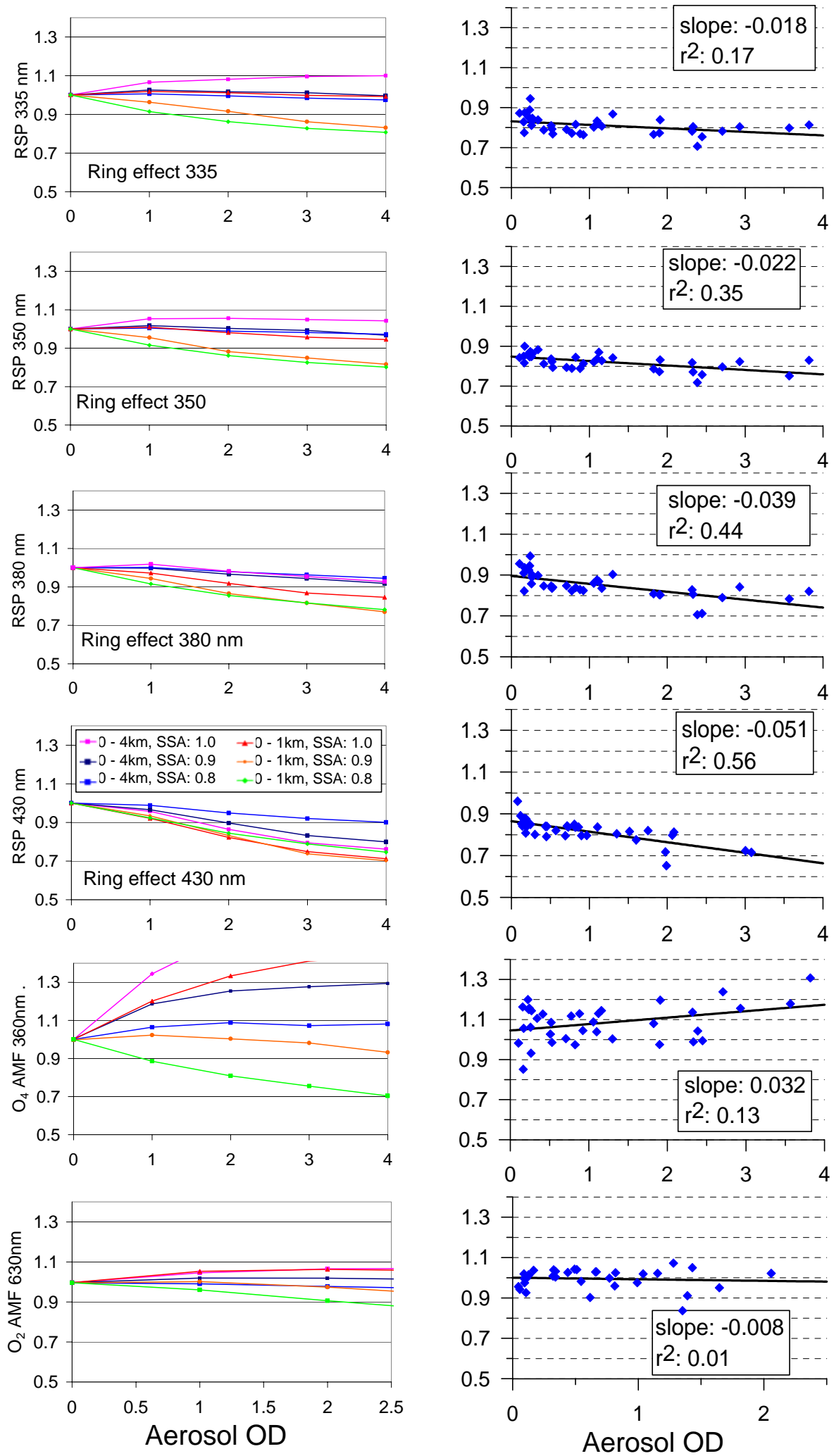

Fig. 12. Observed (right) and simulated (left) dependence of the Ring effect and the $\mathrm{O}_{2}$ and $\mathrm{O}_{4}$ absorptions on the AOD. The data are normalised to model results for an AOD of 0 (see text). The calculations are performed for SZA of $30^{\circ}$ and a viewing angle of $-90^{\circ}$ (nadir). The aerosol asymmetry parameter was assumed to be 0.68 . For $630 \mathrm{~nm}$ the surface albedo was set to $10 \%$; for all other wavelengths it was set to $5 \%$. 

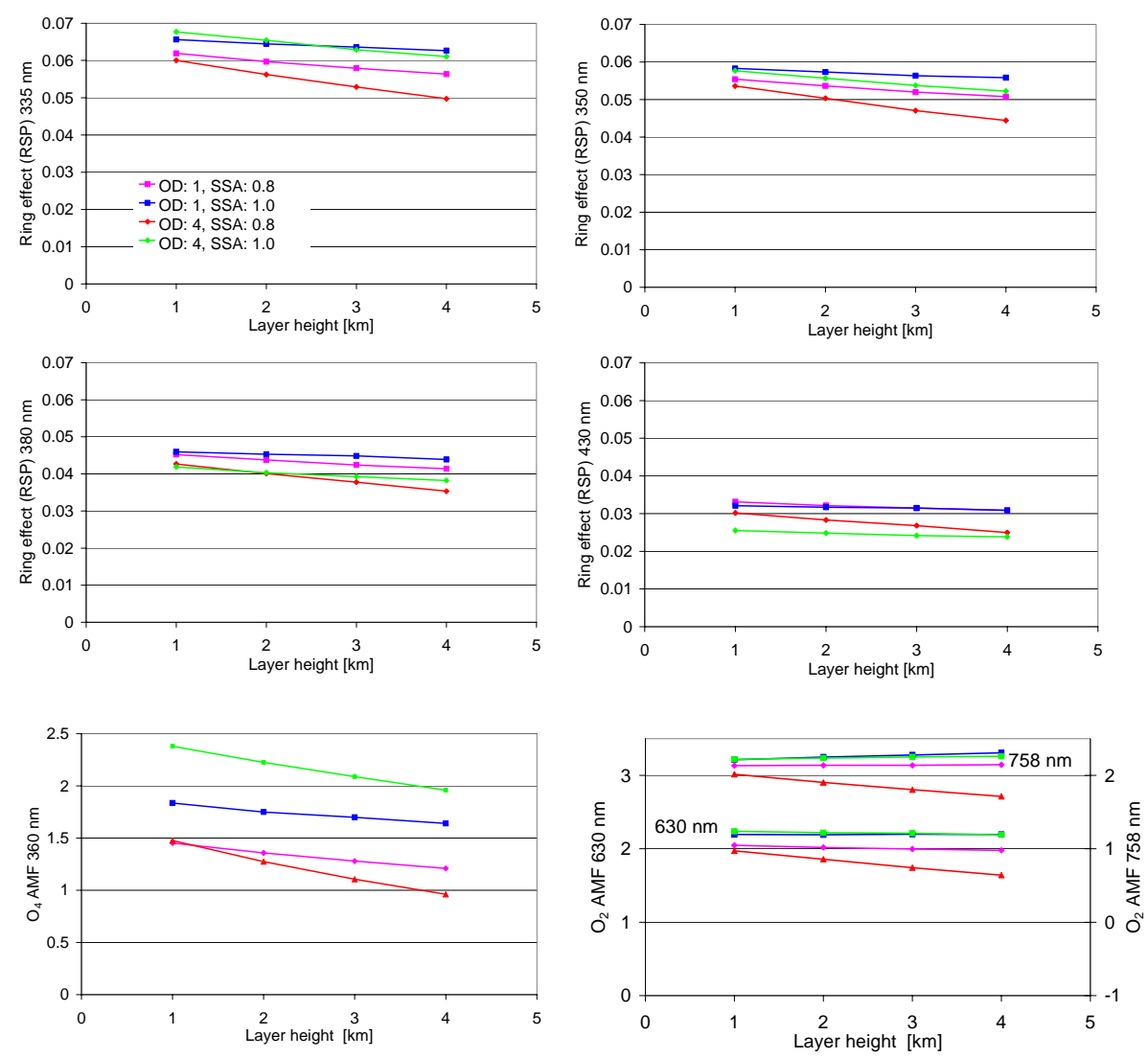

Fig. 13. Dependence of the Ring effect and the $\mathrm{O}_{2}$ and $\mathrm{O}_{4}$ absorptions on the aerosol layer height (the $\mathrm{x}$-axis indicates the upper boundary of the aerosol layer; the lower boundary is the surface). The calculations are performed for SZA of $30^{\circ}$ and a viewing angle of $-90^{\circ}$ (nadir). The aerosol asymmetry parameter was assumed to be 0.68 . For $758 \mathrm{~nm}$ the surface albedo was set to $20 \%$, for $630 \mathrm{~nm}$ to $10 \%$, and for all other wavelengths to $5 \%$.

For the $\mathrm{O}_{4}$ absorption at $360 \mathrm{~nm}$, a systematic increase with increasing AOD is found. This indicates that for the $\mathrm{O}_{4}$ absorptions the albedo effect of aerosols usually dominates over the shielding effect. For the $\mathrm{O}_{2}$ absorptions at $630 \mathrm{~nm}$ almost no dependence on the AOD is found, indicating that the albedo effect and shielding effect broadly cancel each other.

In general, the correlations between the satellite data and AOD from the sun photometer observations are rather low (correlation coefficients $r^{2}<0.6$ ). However, this is not too surprising, because the satellite observations do not only depend on the AOD, but also on the layer height and the singlescattering albedo. Also remaining influences of the viewing angle dependence and the horizontal heterogeneity of the aerosol properties might cause part of the variability.

\subsection{Dependence on aerosol layer height}

Figure 13 presents the dependence of the Ring effect and $\mathrm{O}_{2}$ and $\mathrm{O}_{4}$ absorptions on the aerosol layer height derived from radiative transfer simulations. Here, for almost all quantities and aerosol scenarios a negative dependence is found. For the Ring effect this negative dependence is strongest at short wavelengths. At larger wavelengths other aerosol parameters, like SSA and AOD also start playing a role.

A similar dependence exists for the $\mathrm{O}_{4}$ absorptions at $360 \mathrm{~nm}$, where for all combinations of SSA and AOD decreasing values are found with increasing aerosol layer height.

The $\mathrm{O}_{2}$ absorptions show a slightly different behaviour. Only absorbing aerosols cause a decrease with increasing layer height. For purely scattering aerosols, the $\mathrm{O}_{2}$ absorptions are almost independent on the aerosol layer height. We also simulated the dependence of the normalised radiance for the scenarios shown in Fig. 13; these results are shown in Fig. A6 in the Appendix.

In addition to the sensitivity studies based on radiative transfer simulations, we also searched for observational data to investigate the dependence on the aerosol layer height. One criterion for this search was the availability of (almost) coincident observations from the CALIOP instrument, from which information on the aerosol layer height can be derived (e.g. Winker et al., 2009). 
We especially looked for individual CALIOP observations showing strong variations oft the layer height over small distances, in order to minimise possible complications due to variations of the observational geometry and aerosol properties. Another criterion was the presence of high AOD to ensure a strong effect on the satellite observations. Thus the search was focussed on the Beijing area, because of the high AOD expected there. We identified one interesting example (area south of Beijing, 16 September 2006), for which the above mentioned conditions were fulfilled. MODIS observations are used to ensure that the selected area is nearly free of clouds (see Fig. 14). From sun photometer measurements at the AERONET station in Beijing and from MODIS observations the AOD was found to range between 2 and 3. From CALIOP measurements at around 05:30 UTC we estimate an increase in aerosol layer height from about $1.5 \mathrm{~km}$ at $40^{\circ} \mathrm{N}$ to about $2.5 \mathrm{~km}$ altitude at $37^{\circ} \mathrm{N}$ (http://www-calipso.larc.nasa. gov/products/lidar/browse_images/production/). The track of the CALIOP overpass is indicated by the black line in Fig. 14. From the SCIAMACHY observations we chose only the eastern part of the swath (with the same viewing angles for all latitudes) to minimise the influence of the viewing angle on the analysed quantities. The selected SCIAMACHY ground pixels are indicated by the red box in Fig. 14.

The results of the Ring effect and the $\mathrm{O}_{2}$ and $\mathrm{O}_{4}$ absorptions for the selected SCIAMACHY observations are shown in Fig. 15. Also shown are results from radiative transfer simulations assuming a linear increase of the aerosol layer height from 1 to $2.5 \mathrm{~km}$ between $40^{\circ} \mathrm{N}$ and $37^{\circ} \mathrm{N}$. The SSA was set to 0.95 , and the AOD was set to 3 for wavelengths in the UV and blue spectral range and to 1.5 for $630 \mathrm{~nm}$. Note that these aerosol properties can of course be only a rough representation for the true values, especially because of the rather large time difference between the SCIAMACHY and CALIOP observations (about $3.5 \mathrm{~h}$ ).

For the Ring effect, a general decrease with increasing layer height is found at all wavelengths. However, at short wavelengths, the model simulations systematically overestimate the observations. Part of this discrepancy might be related to the strong polarisation sensitivity of the SCIAMACHY instrument. Another reason for this discrepancy might be an increasing AOD and/or decreasing SSA with decreasing wavelength (see also Sect. 4.6). For the Ring effect observations at $380 \mathrm{~nm}$ and $430 \mathrm{~nm}$ a local minimum around $1.5 \mathrm{~km}$ altitude is observed, which is probably related to an increase of the AOD at these locations (probably caused by local cloud presence; the sensitivity of the Ring effect to AOD increases with wavelength, see Fig. 11). Indications for locally increased AOD are also found from other observations (see below).

Besides these deviations, the systematic dependence on layer height is in general well described by the simulations using the assumed aerosol properties.

For the $\mathrm{O}_{2}$ and $\mathrm{O}_{4}$ absorptions no clear dependencies on the aerosol layer height are observed. This indicates the

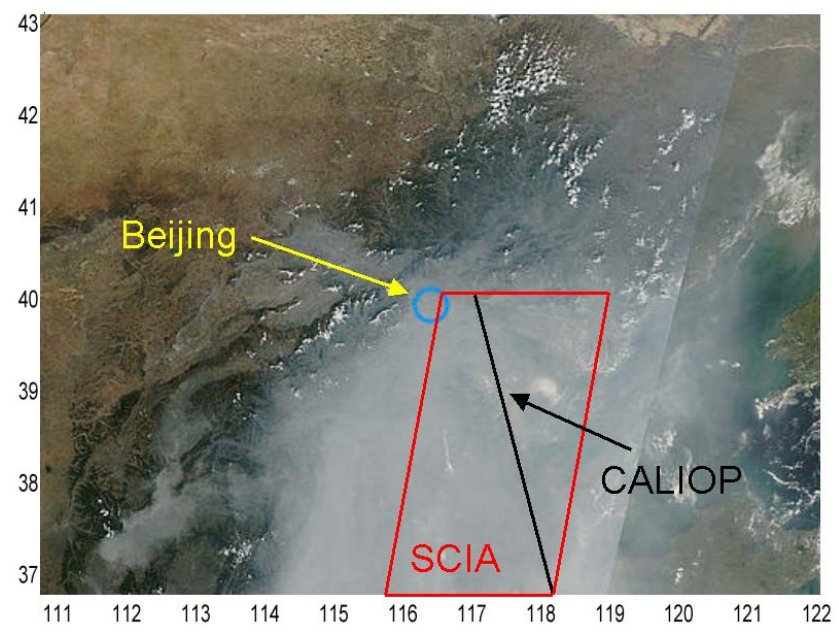

Fig. 14. MODIS RGB image for a day with strong aerosol pollution (16 September 2006) over the area around over Beijing (AOD between 2 and 3). Near-simultaneous CALIOP measurements indicate that the aerosol layer height between about $40^{\circ} \mathrm{N}$ and $37^{\circ} \mathrm{N}$ increased from about $1 \mathrm{~km}$ to $2.5 \mathrm{~km}$.

competing influences of the shielding effect and albedo effect. For aerosol altitudes around $1.5 \mathrm{~km}$, both the $\mathrm{O}_{2}$ and $\mathrm{O}_{4}$ absorptions show local maxima, also indicating an increased $\mathrm{AOD}$ at these locations, maybe due to the presence of thin clouds.

In Figure 16, the dependence of the observed and simulated normalised radiances on layer height is presented. Overall good agreement is found, especially taking into account the fact that the true AOD (and SSA and $g$ ) is not known. Around a layer height of $1.5 \mathrm{~km}$ enhanced values of the normalised radiance are found confirming the assumption of a locally increased AOD (probably caused by local cloud presence). In contrast, the rather low values at about $1 \mathrm{~km}$ indicate that the AOT at these locations might be smaller than assumed in the radiative transfer simulations.

\subsection{Dependence on aerosol single scattering albedo}

The sensitivity of the observations to the aerosol single scattering albedo (SSA) is investigated using radiative transfer simulations. The respective results of the Ring effect and the $\mathrm{O}_{4}$ and $\mathrm{O}_{2}$ absorption are shown in Fig. 17. For the Ring effect, a (positive) dependence on the SSA is found only at small wavelengths $(335$ and $350 \mathrm{~nm}$ ). The reason is that a layer of absorbing aerosols shields the atmosphere below it from view of the satellite instrument, thereby decreasing the Raman scattering probability for the observed photons. In contrast, non-absorbing aerosols tend to increase the Raman scattering probability, because after being scattered by an aerosol particle, the photon is very likely to be scattered again by a molecule due to the high probability of molecular scattering at short wavelengths. 

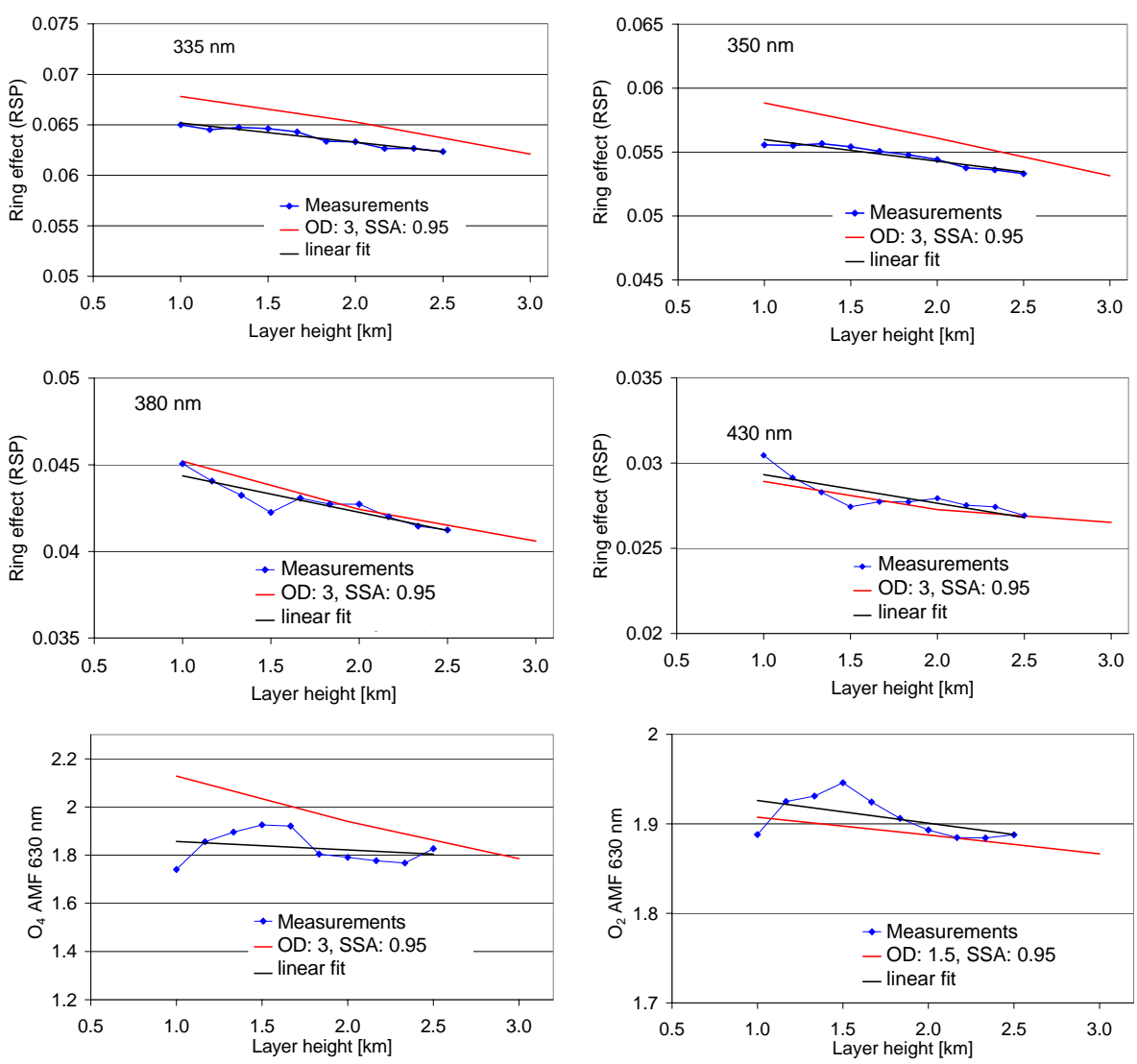

Fig. 15. Observed (blue dots) and simulated dependency of the Ring effect and the $\mathrm{O}_{4}$ and $\mathrm{O}_{2}$ absorption on the aerosol layer height over the area south of Beijing on 17 September 2006 (see Fig. 14). For the radiative transfer calculations the following properties were assumed: surface albedo: $10 \%(630 \mathrm{~nm})$ and 5\% (all other wavelengths), aerosol SSA: 0.95; $g$ : 0.68, AOD: 1.5 (630 nm) and 3 (all other wavelengths). Note that the simulated $\mathrm{O}_{2}$ AMFs were corrected for the saturation effect (see Sect. 3).

In contrast, Ring effect observations at larger wavelengths depend only weakly on the aerosol SSA. For these wavelengths, the effect of absorbing aerosols is similar compared to shorter wavelengths. But now, due to the decreased probability of molecular scattering, non-absorbing aerosols also tend to decrease the Raman scattering probability. Thus the influence of the aerosol SSA on the Ring effect is much weaker at larger wavelengths ( 380 and $430 \mathrm{~nm}$ ) compared to short wavelengths.

For the absorptions of $\mathrm{O}_{2}$ and $\mathrm{O}_{4}$, an increase with increasing SSA is found for all aerosol scenarios. With decreasing aerosol SSA the probability for photons from low atmospheric layers to reach the satellite instrument decreases, shortening the average light path length, and leading to decreased absorption by $\mathrm{O}_{4}$ and $\mathrm{O}_{2}$.

For the observed radiance, shown in Fig. A7 in the Appendix, a strong increase with increasing aerosol SSA is found. The strongest (relative) dependence occurs for large wavelengths, for which the scattering on molecules is relatively weak.

\subsection{Dependence on aerosol asymmetry parameter}

The sensitivity of the observations to the aerosol asymmetry parameter $(g)$ is also investigated using radiative transfer simulations. The effect of the aerosol asymmetry parameter to the observed quantities is similar to that of the aerosol single scattering albedo. With increasing $g$ (or decreasing SSA) less radiation is directly backscattered to the satellite sensor. Thus especially the observed radiance depends strongly on the aerosol $g$ (and aerosol SSA), see Fig. A8 in the Appendix. Nevertheless, there is also an important difference between the effects of aerosol $g$ and SSA: while for SSA $<1$ photons are absorbed and thus removed from the radiation field, the variation of $g$ only affects the distribution of atmospheric light paths. Thus in general for the Ring effect and the absorptions of $\mathrm{O}_{2}$ and $\mathrm{O}_{4}$ weaker dependencies are found compared to the influence of the aerosol SSA (see Fig. 18).

Interestingly the dependencies of the $\mathrm{O}_{4}$ and $\mathrm{O}_{2}$ absorptions on $g$ are quite different. This is mainly caused by the difference in wavelength. For short wavelengths multiple scattering is more important than for large wavelengths. Since aerosols with smaller $g$ scatter less photons in forward 

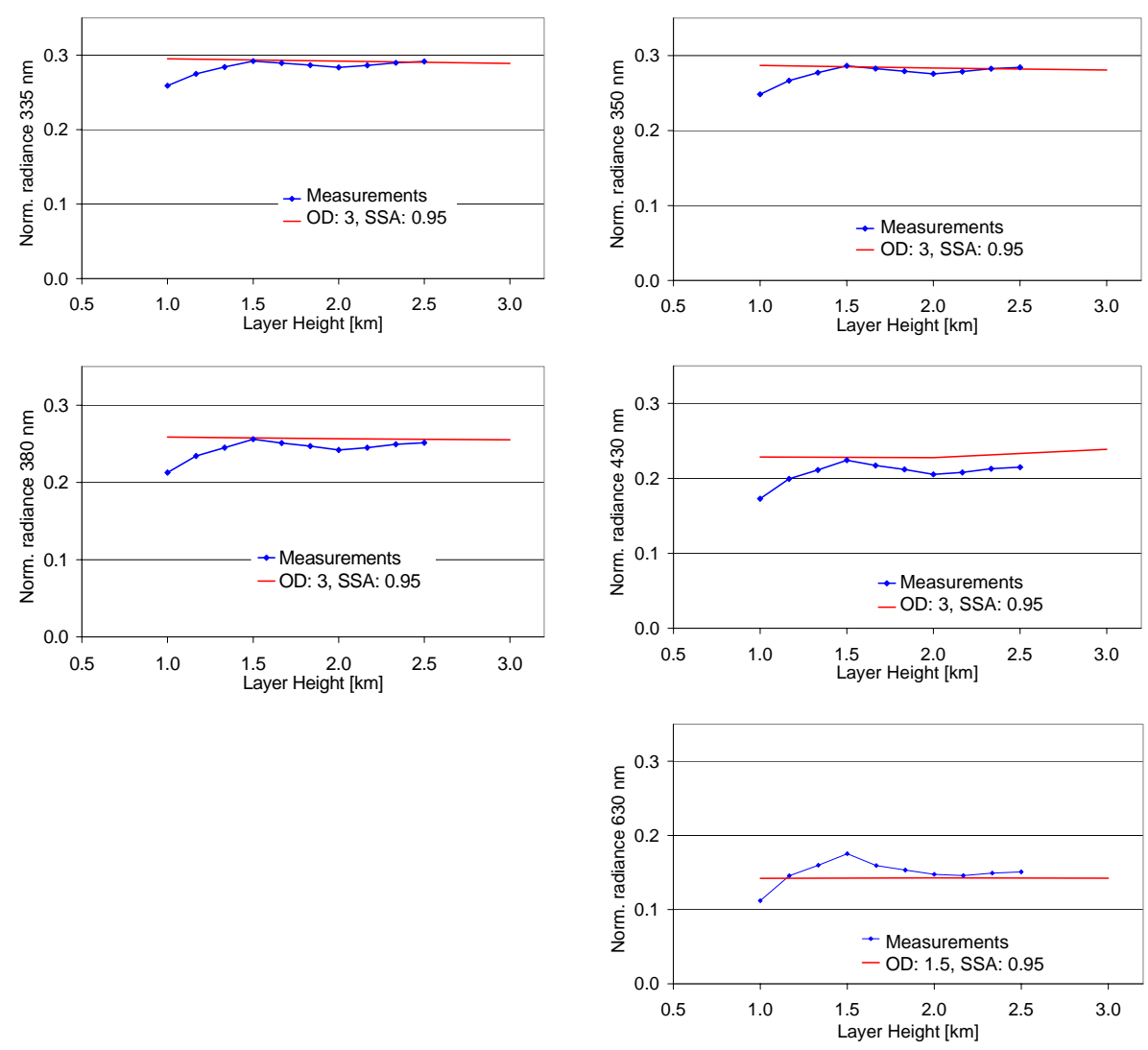

Fig. 16. Observed (blue dots and lines) and simulated (red lines) dependency of the normalised radiance on the aerosol layer height over the area south of Beijing on 17 September 2006 (see Fig. 14). For the radiative transfer calculations the following properties were assumed: surface albedo: $10 \%(630 \mathrm{~nm})$ and 5\% (all other wavelengths), aerosol SSA: 0.95; $g$ : 0.68, AOD: 1.5 (630 nm) and 3 (all other wavelengths).

direction they lead to a stronger increase of multiple scattering and thus to larger absorption paths in the UV.

\section{Conclusions and outlook}

In this study we explored the potential of satellite observations of the Ring effect to retrieve aerosol properties. Compared to clouds, the influence of aerosols on the Ring effect is rather weak because the optical depth of aerosols is usually much smaller than that of clouds. In addition, atmospheric aerosols are usually located at low altitude and therefore shield only a small fraction of the total atmospheric column. Fortunately, the Ring effect is a rather strong signal in the UV spectral range and thus can be typically analysed with high accuracy.

We analysed observations of the satellite instrument SCIAMACHY on ENVISAT, because it provides continuous spectra of the earth shine radiance with moderate spectral resolution over a large wavelength range. In addition to the observations of the Ring effect at various wavelengths $(335 \mathrm{~nm}, 350 \mathrm{~nm}, 380 \mathrm{~nm}$, and $430 \mathrm{~nm})$, we also investigated observations of the atmospheric absorptions of $\mathrm{O}_{4}$ (at
$360 \mathrm{~nm}$ ) and $\mathrm{O}_{2}$ (at $630 \mathrm{~nm}$ ) and the normalised radiance (at $335 \mathrm{~nm}, 350 \mathrm{~nm}, 380 \mathrm{~nm}, 430 \mathrm{~nm}$, and $630 \mathrm{~nm}$ ). Like the Ring effect, these observations are systematically affected by the presence of aerosols (see e.g. Kokhanovsky et al., 2010).

In addition to the SCIAMACHY observations we also performed radiative transfer simulations of the observed quantities. Here also simulations of the $\mathrm{O}_{2} \mathrm{~A}$ band at $758 \mathrm{~nm}$ were included.

The influence of aerosols on observations of Ring effect and the $\mathrm{O}_{2}$ and $\mathrm{O}_{4}$ absorptions could be well demonstrated in this study, and in general, the observations agree well with model simulations.

From our observations we derive the following main conclusions:

- Observations of the Ring effect depend on several aerosol properties like AOD, single scattering albedo, phase function, and layer height.

- Depending on the selected wavelength range, Ring effect observations are especially sensitive to specific aerosol properties: at short wavelengths, the dependence on layer height and SSA is more pronounced; at 

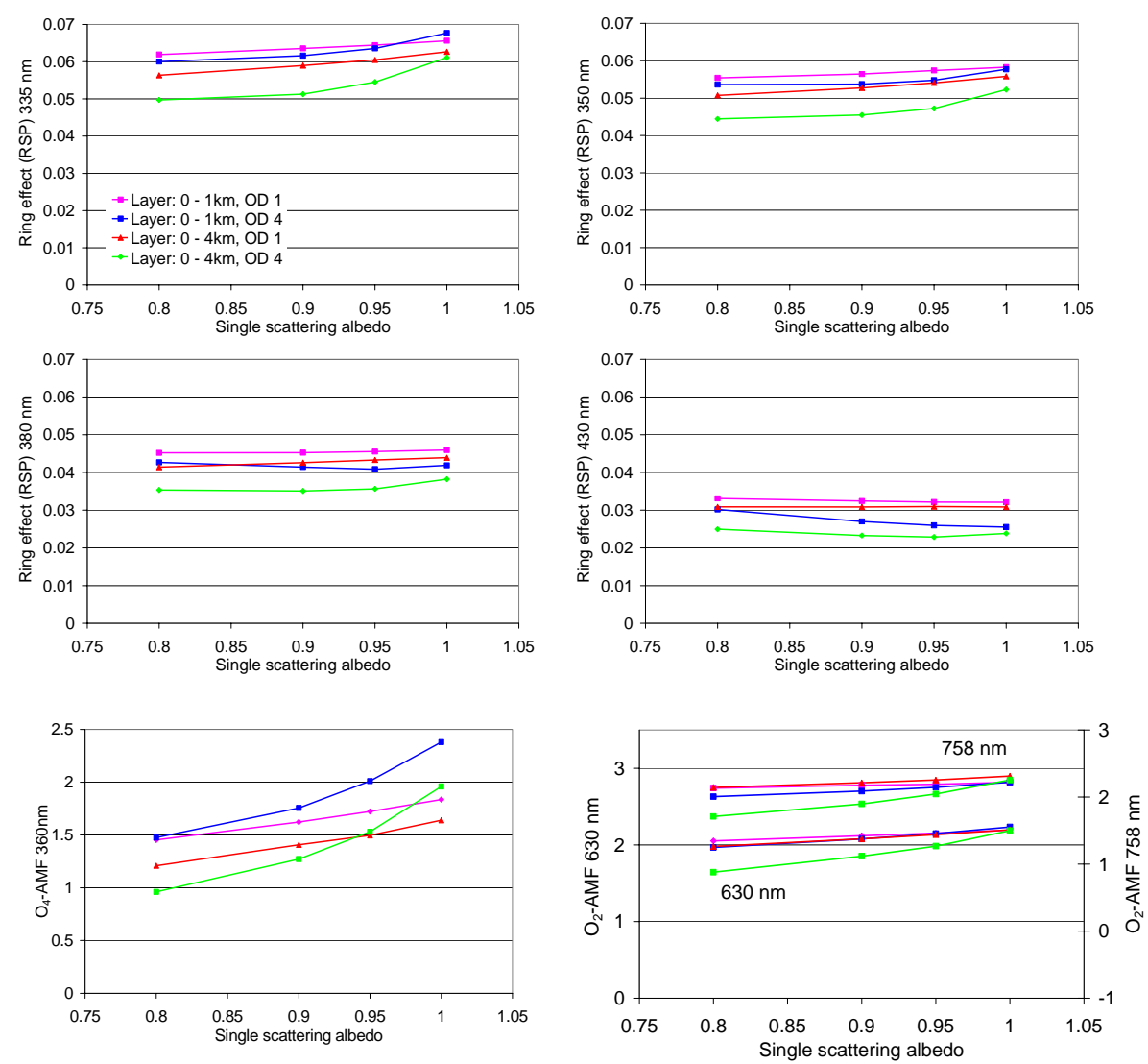

Fig. 17. Dependence of the Ring effect and the $\mathrm{O}_{2}$ and $\mathrm{O}_{4}$ absorptions on the aerosol single scattering albedo. The calculations are performed for SZA of $30^{\circ}$ and a viewing angle of $-90^{\circ}$ (nadir geometry). The aerosol asymmetry parameter was assumed to be 0.68 . For 758 nm the surface albedo was set to $20 \%$, for $630 \mathrm{~nm}$ to $10 \%$, and for all other wavelengths to $5 \%$.

large wavelengths the dependence on AOD is more pronounced.

- The influence of the surface albedo on the Ring effect and the gas absorptions is quite different. For low albedo, the Ring effect first decreases with increasing albedo. After reaching a minimum (between $20 \%$ and $50 \%$, depending on wavelength) the Ring effect starts increasing again. In contrast, the absorptions of $\mathrm{O}_{4}$ and $\mathrm{O}_{2}$ increase steadily with increasing albedo.

- In contrast to observations at large wavelengths the spatio-temporal variation of the surface albedo is rather small (except for snow and ice), minimising the uncertainties in the interpretation of the observations at these wavelengths.

- In principle the strength of the Ring effect can be analysed with high accuracy (on the order of $1 \%$ or below). Assuming that the optical aerosol properties are known from independent sources, this accuracy transforms e.g. into an uncertainty of the height retrieval between about $200 \mathrm{~m}$ and $1000 \mathrm{~m}$ (depending on the aerosol properties). Unfortunately, due to the strong polarisation sensitivity of the SCIAMACHY instrument the high accuracy of the Ring retrievals might not be fully exploited in actual retrieval applications. We would like to encourage the OMI retrieval teams to investigate the accuracy of Ring retrievals from OMI observations at different wavelengths.

- For observations of the $\mathrm{O}_{2}$ and $\mathrm{O}_{4}$ absorption the shielding effect and albedo effect of aerosols have opposing effects, often (partly) compensating each other. Thus from such observations alone, in certain cases aerosol effects might be difficult to identify. In contrast, for Ring effect observations the shielding effect and albedo effect mainly work in the same direction (particularly for $430 \mathrm{~nm}$ ), thus aerosols typically lead to a decrease of the Ring effect in satellite observations.

Our study indicates that Ring effect observations might be very well suited for the retrieval of aerosol properties from space. From the synergistic use of Ring effect analyses at different wavelengths it should be possible to extract different aerosol properties like AOD, single scattering albedo 

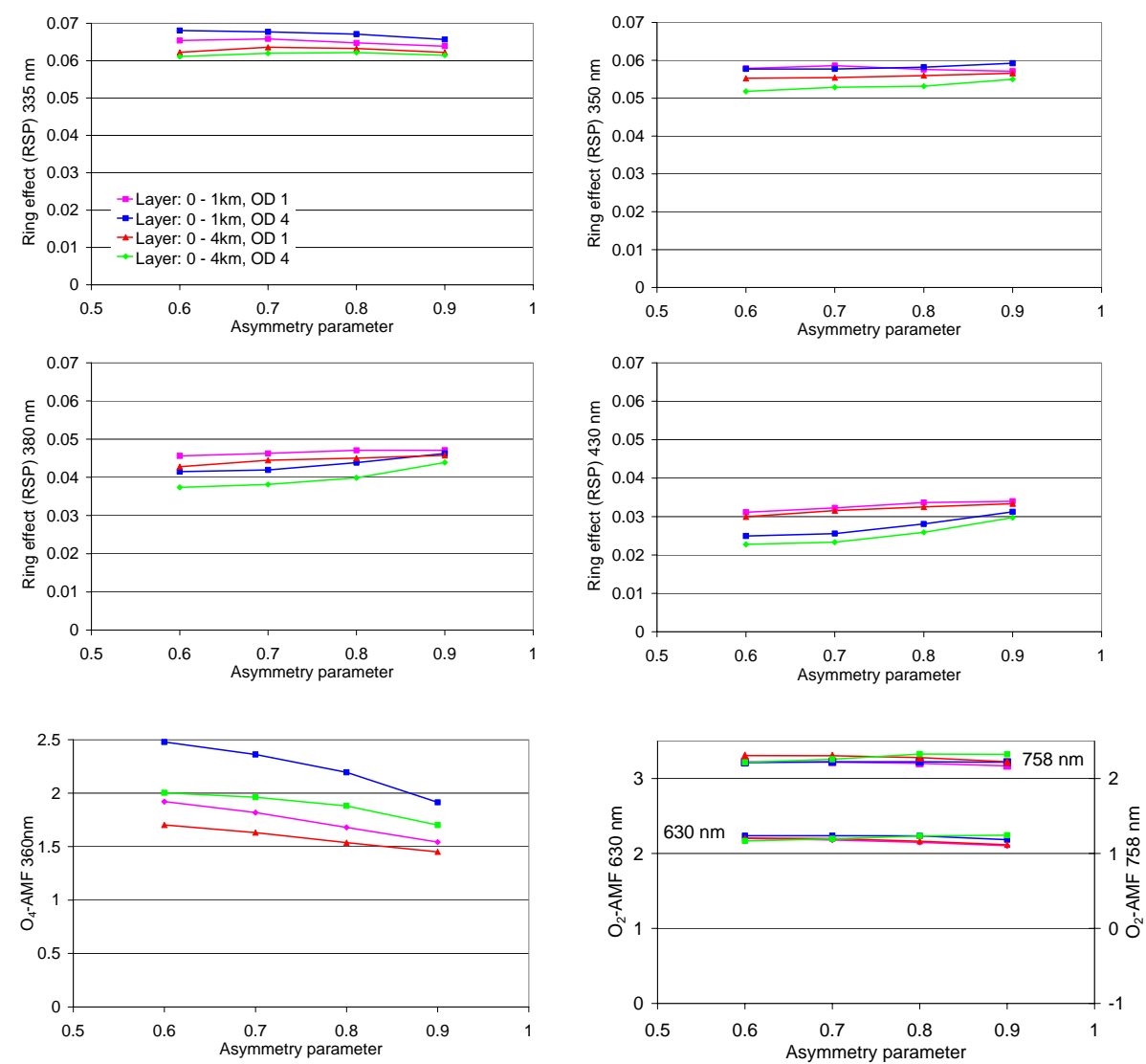

Fig. 18. Dependence of the Ring effect and the $\mathrm{O}_{2}$ and $\mathrm{O}_{4}$ absorptions on the aerosol asymmetry parameter $g$. The calculations are performed for aerosol single scattering albedo of $1, \mathrm{SZA}$ of $30^{\circ}$, and a viewing angle of $-90^{\circ}$ (nadir geometry). For $758 \mathrm{~nm}$ the surface albedo was set to $20 \%$, for $630 \mathrm{~nm}$ to $10 \%$, and for all other wavelengths to $5 \%$.

and layer height. Similar conclusions were also derived by Vasilkov et al. (2006). If possible, also further quantities like the normalised radiance or the absorptions of $\mathrm{O}_{4}$ and $\mathrm{O}_{2}$ should be simultaneously analysed and used in the aerosol retrieval.

While in this study the specific dependencies of the observed quantities on aerosol properties were investigated separately for each quantity and wavelength, future studies should aim in simultaneously fitting the results of realistic aerosol models to all observed quantities. Such inverse modelling approaches might be most promising for observations from OMI and future satellite instruments with negligible polarisation sensitivity and small ground pixel sizes.

\section{Appendix A}

\section{Additional radiative transfer modelling results}

This appendix shows results of additional radiative transfer simulations, which complement the results shown in the main part of the paper. Most of these results were already discussed in the respective sections of the paper. Additional discussion on the results for the viewing angle dependence are presented below.

In Fig. A2, the simulated dependencies of the Ring effect and the $\mathrm{O}_{4}$ and $\mathrm{O}_{2}$ absorptions on the viewing angle are shown. The SZA was set to $30^{\circ}$ with the sun shining from the east (like for the SCIAMACHY observations).

For the Ring effect in most cases an increase with increasing viewing angle is found. Like for the dependence on SZA, this can be explained by the direct relationship of the scattering angle to the viewing angle. For increasing viewing angle the scattering angle comes closer to $90^{\circ}$ (because the SZA is $>0^{\circ}$ ) and thus the strength of the Ring effect increases (see Fig. 4). It is interesting to note that for small wavelengths, this systematic behaviour is found not only for an aerosol-free case, but also for various aerosol scenarios. In contrast, with increasing wavelength, the dependence of the Ring effect on viewing angle becomes progressively weaker for most aerosol scenarios. For Ring effect observations at $430 \mathrm{~nm}$, even a slight decrease with increasing viewing angle can be found for aerosol scenarios with high AOD, high layer height and high SSA. In these cases, scattering 

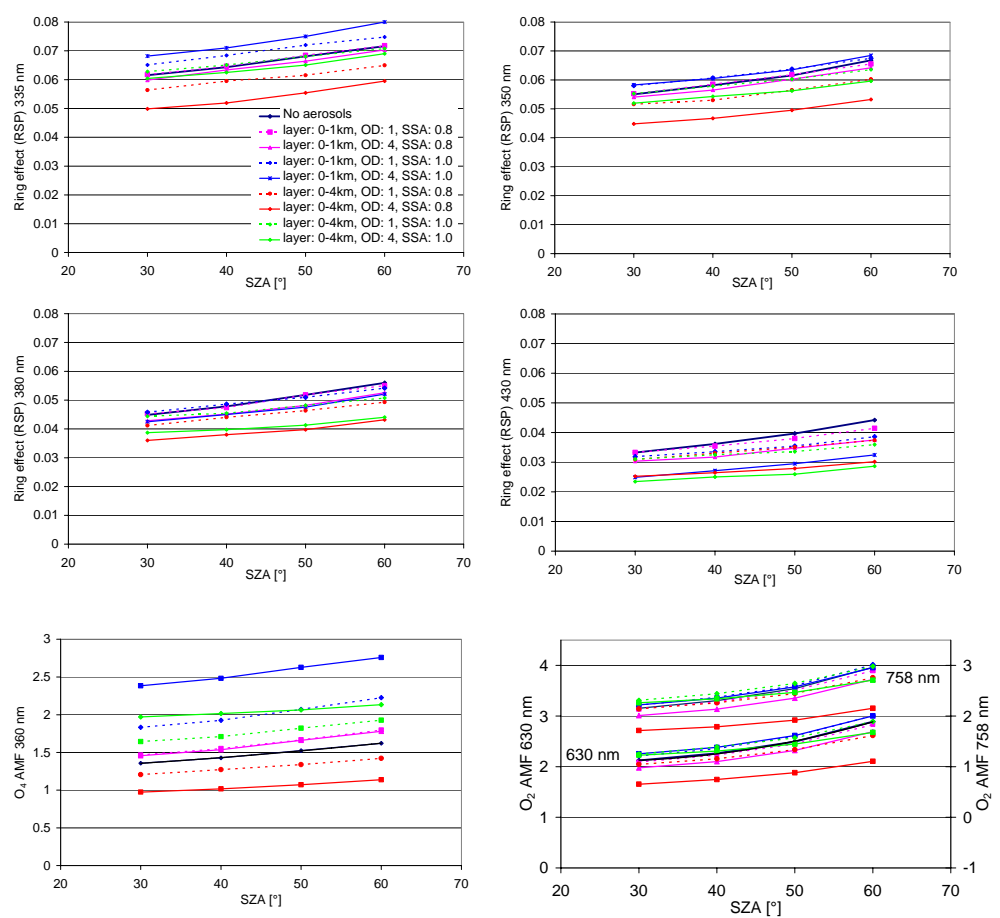

Fig. A1. Modelled dependence of the Ring effect and the $\mathrm{O}_{2}$ and $\mathrm{O}_{4}$ absorptions on the solar zenith angle. The calculations are performed for a viewing angle of $-90^{\circ}$ (nadir geometry), aerosol asymmetry parameter of 0.68 , and surface albedo of $10 \%$ for $630 \mathrm{~nm}, 20 \%$ for $758 \mathrm{~nm}$, and $5 \%$ for all other wavelengths.
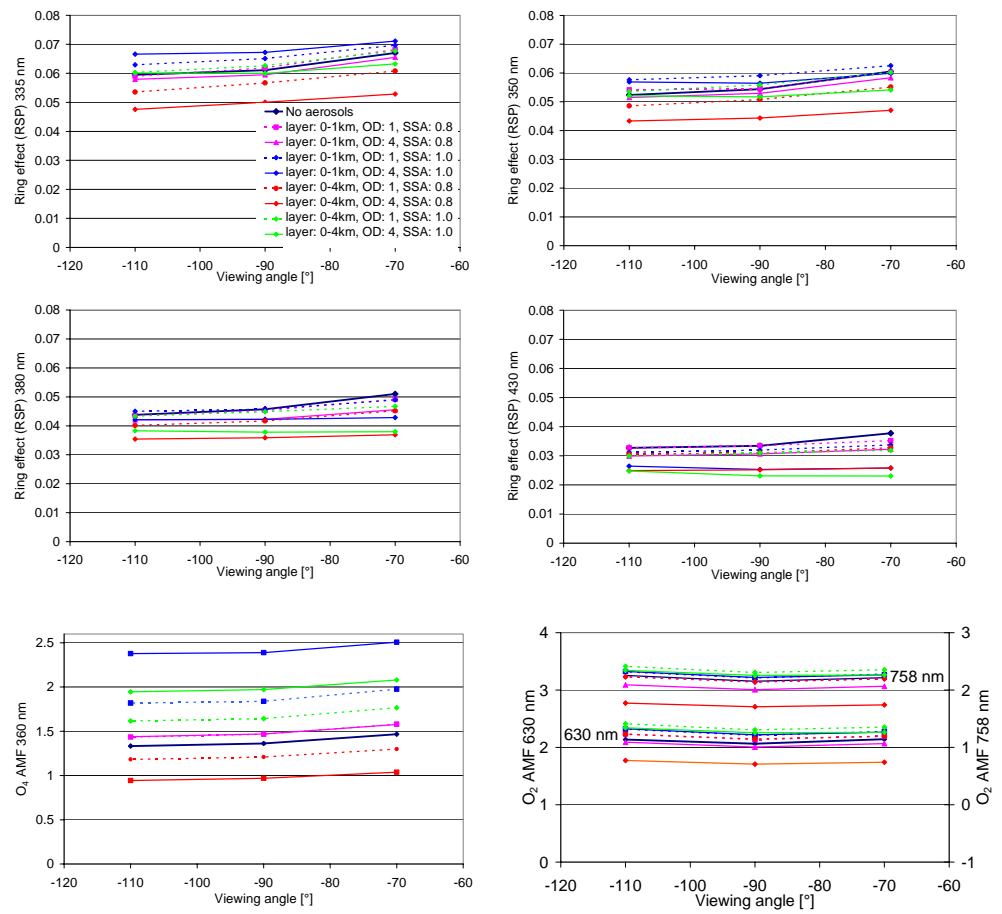

Fig. A2. Dependence of the Ring effect and the $\mathrm{O}_{2}$ and $\mathrm{O}_{4}$ absorptions on the viewing zenith angle of the satellite instrument (angles larger than $-90^{\circ}$ indicate eastern direction). The calculations are performed for SZA of $30^{\circ}$ with the sun in eastern direction. The aerosol asymmetry parameter was assumed to be 0.68 . For $758 \mathrm{~nm}$ the surface albedo was set to $20 \%$, for $630 \mathrm{~nm}$ to $10 \%$, and for all other wavelengths to $5 \%$. 

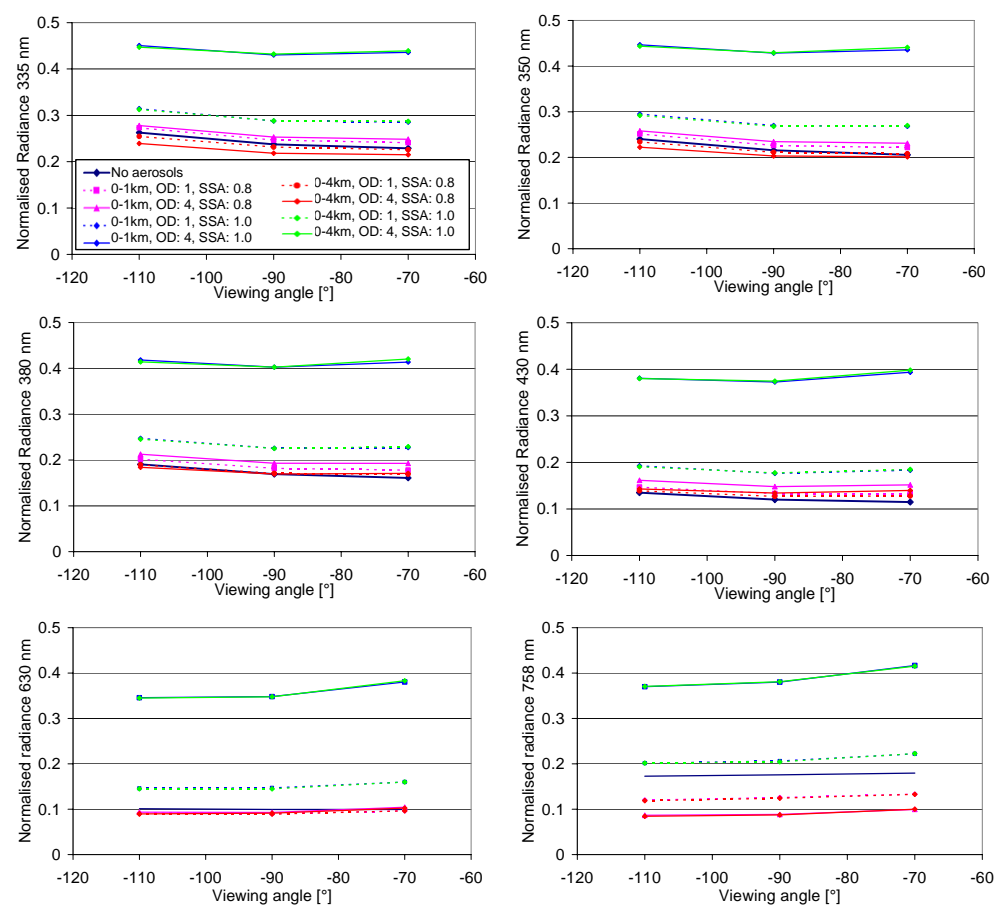

Fig. A3. Dependence of the normalised radiances on the viewing zenith angle of the satellite instrument (angles larger than $-90^{\circ}$ indicate eastern direction). The calculations are performed for SZA of $30^{\circ}$ with the sun in eastern direction. The aerosol asymmetry parameter was assumed to be 0.68 . For $758 \mathrm{~nm}$ the surface albedo was set to $20 \%$, for $630 \mathrm{~nm}$ to $10 \%$, and for all other wavelengths to $5 \%$.
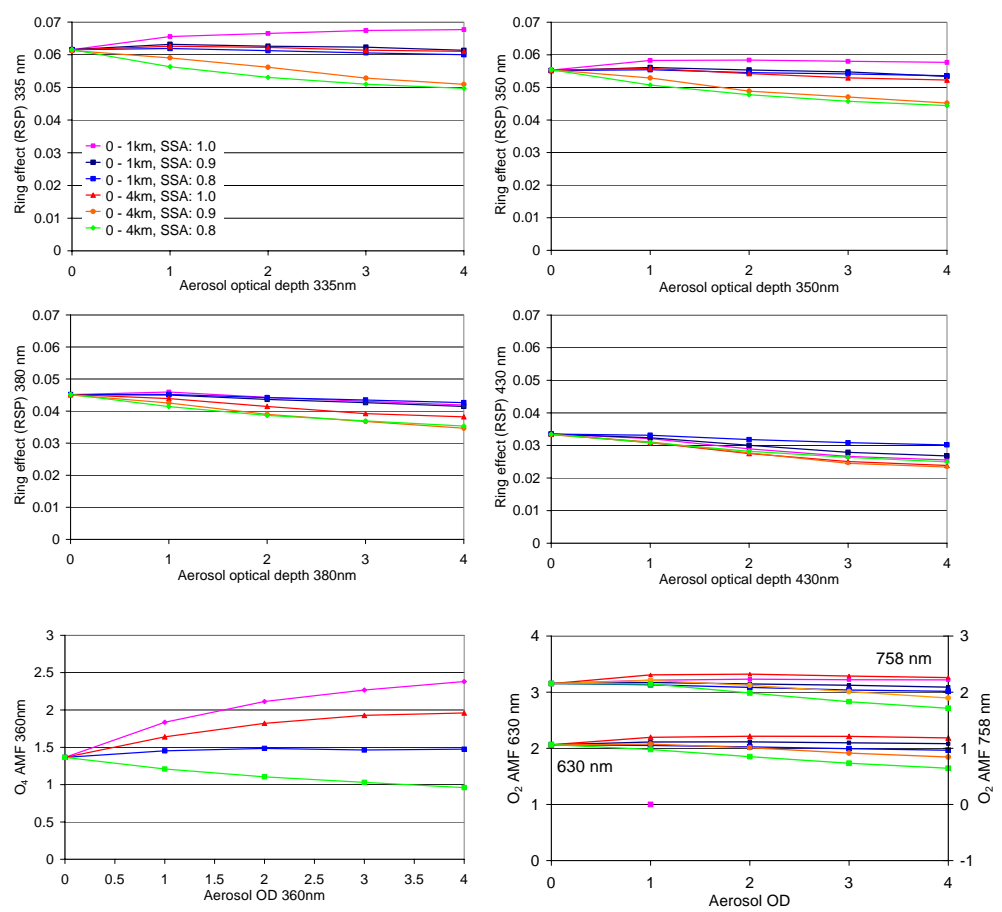

Fig. A4. Dependence of the Ring effect and the $\mathrm{O}_{2}$ and $\mathrm{O}_{4}$ absorptions on the AOD. The calculations are performed for SZA of $30^{\circ}$ and a viewing angle of $-90^{\circ}$ (nadir geometry). The aerosol asymmetry parameter was assumed to be 0.68 . For $758 \mathrm{~nm}$ the surface albedo was set to $20 \%$, for $630 \mathrm{~nm}$ to $10 \%$, and for all other wavelengths to $5 \%$. 

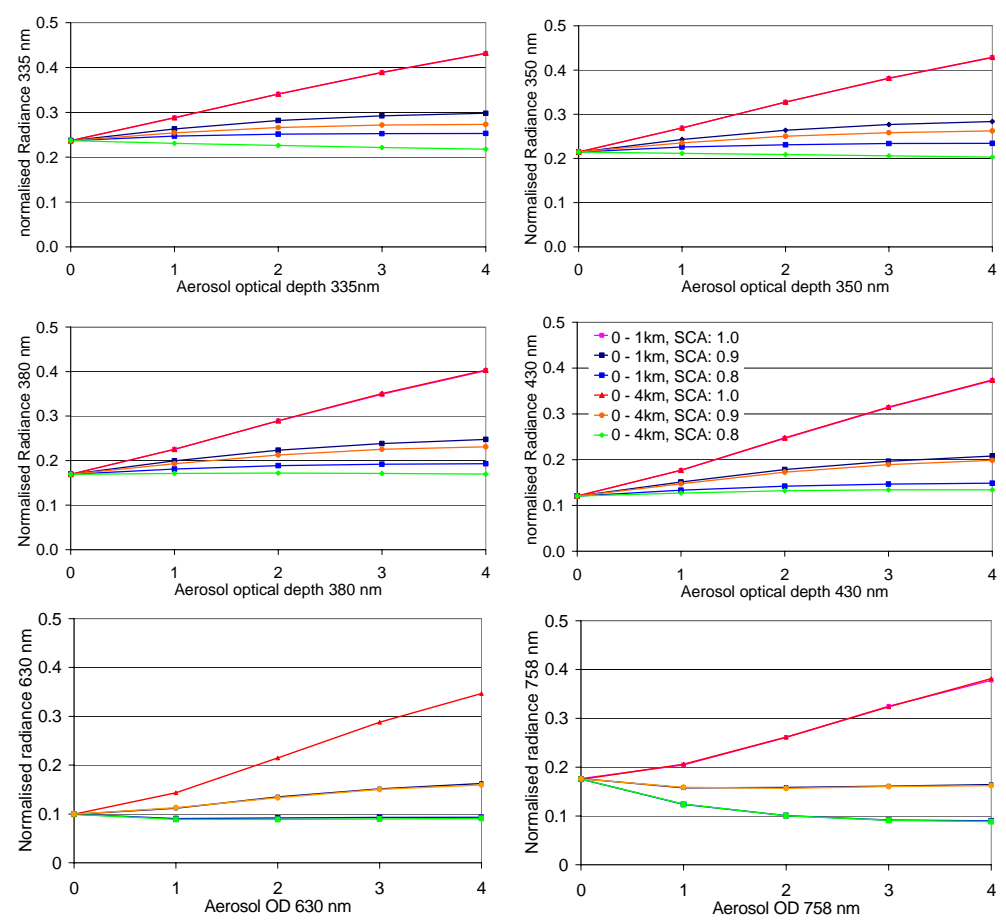

Fig. A5. Dependence of the normalised radiance on the AOD. The calculations are performed for SZA of $30^{\circ}$ and a viewing angle of $-90^{\circ}$ (nadir geometry). The aerosol asymmetry parameter was assumed to be 0.68 . For $758 \mathrm{~nm}$ the surface albedo was set to $20 \%$, for $630 \mathrm{~nm}$ to $10 \%$, and for all other wavelengths to $5 \%$.
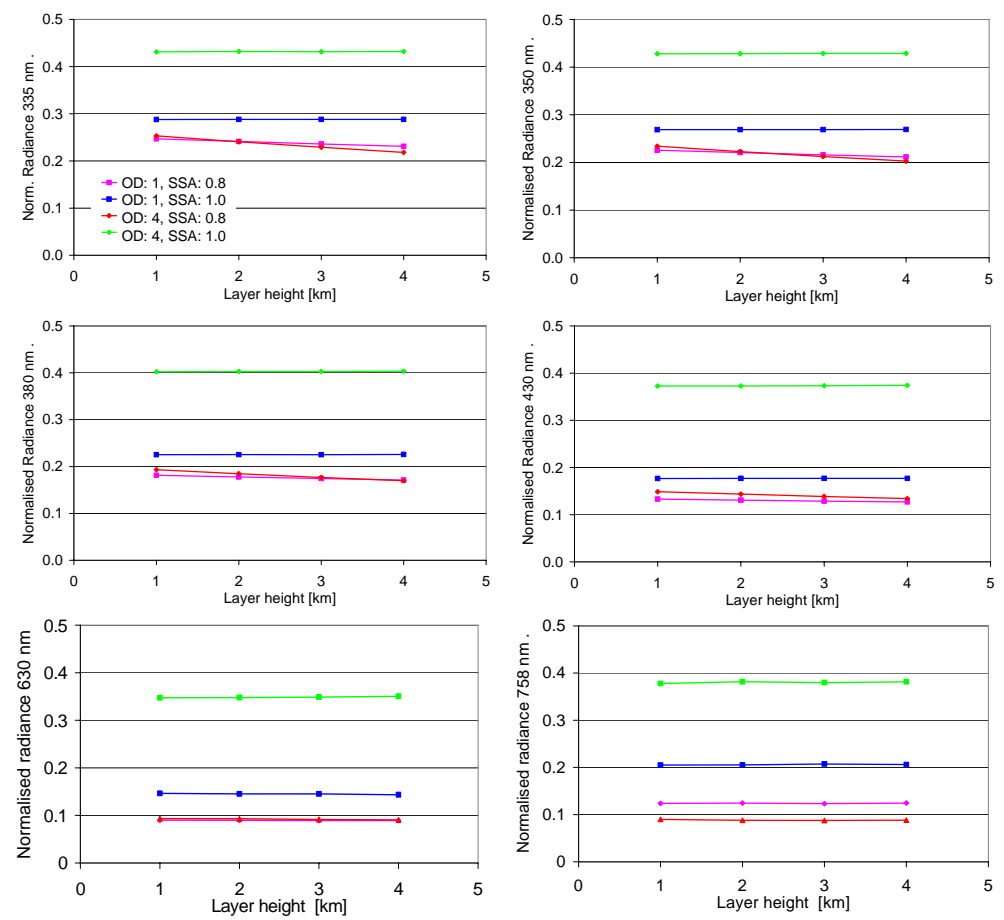

Fig. A6. Dependence of the normalised radiance on the aerosol layer height (the x-axis indicates the upper boundary of the aerosol layer; the lower boundary is the surface). The calculations are performed for SZA of $30^{\circ}$ and viewing angle of $-90^{\circ}$ (nadir). The aerosol asymmetry parameter was assumed to be 0.68 . For $758 \mathrm{~nm}$ the surface albedo was set to $20 \%$, for $630 \mathrm{~nm}$ to $10 \%$, and for all other wavelengths to $5 \%$. 

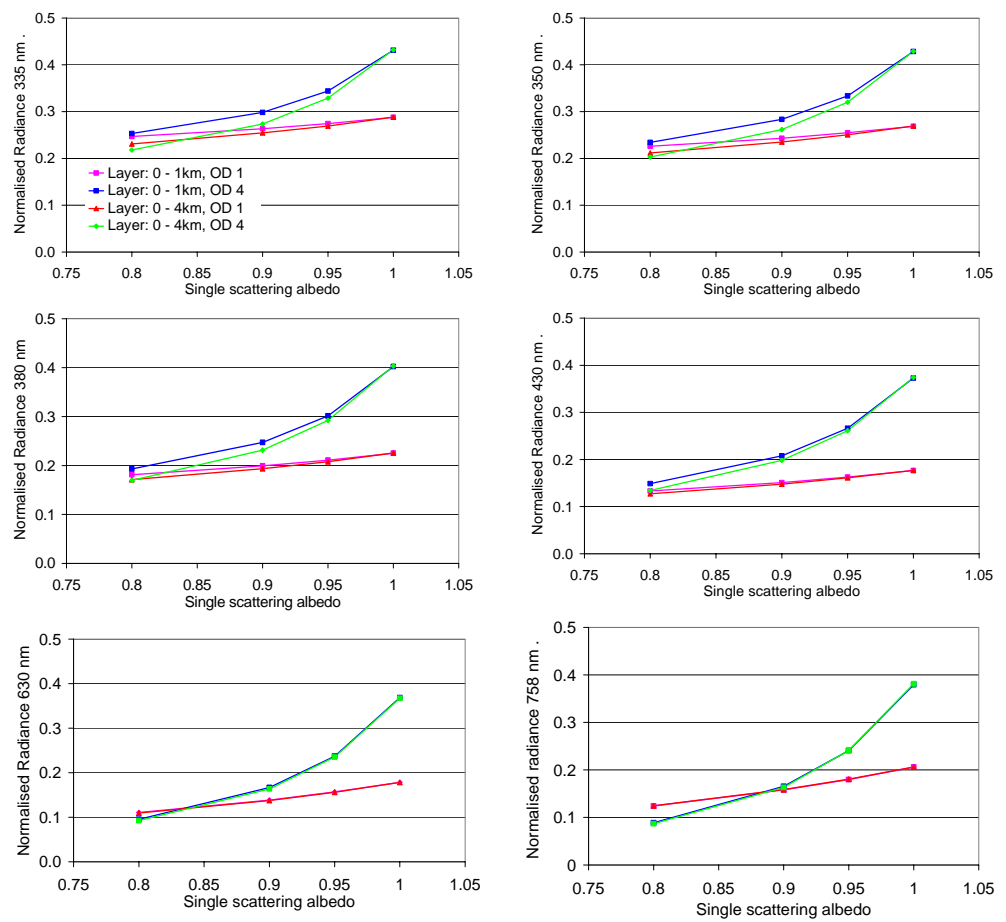

Fig. A7. Dependence of the normalised radiance on the aerosol single scattering albedo. The calculations are performed for SZA of $30^{\circ}$ and a viewing angle of $-90^{\circ}$ (nadir geometry). The aerosol asymmetry parameter was assumed to be 0.68 . For $758 \mathrm{~nm}$ the surface albedo was set to $20 \%$, for $630 \mathrm{~nm}$ to $10 \%$, and for all other wavelengths to $5 \%$.
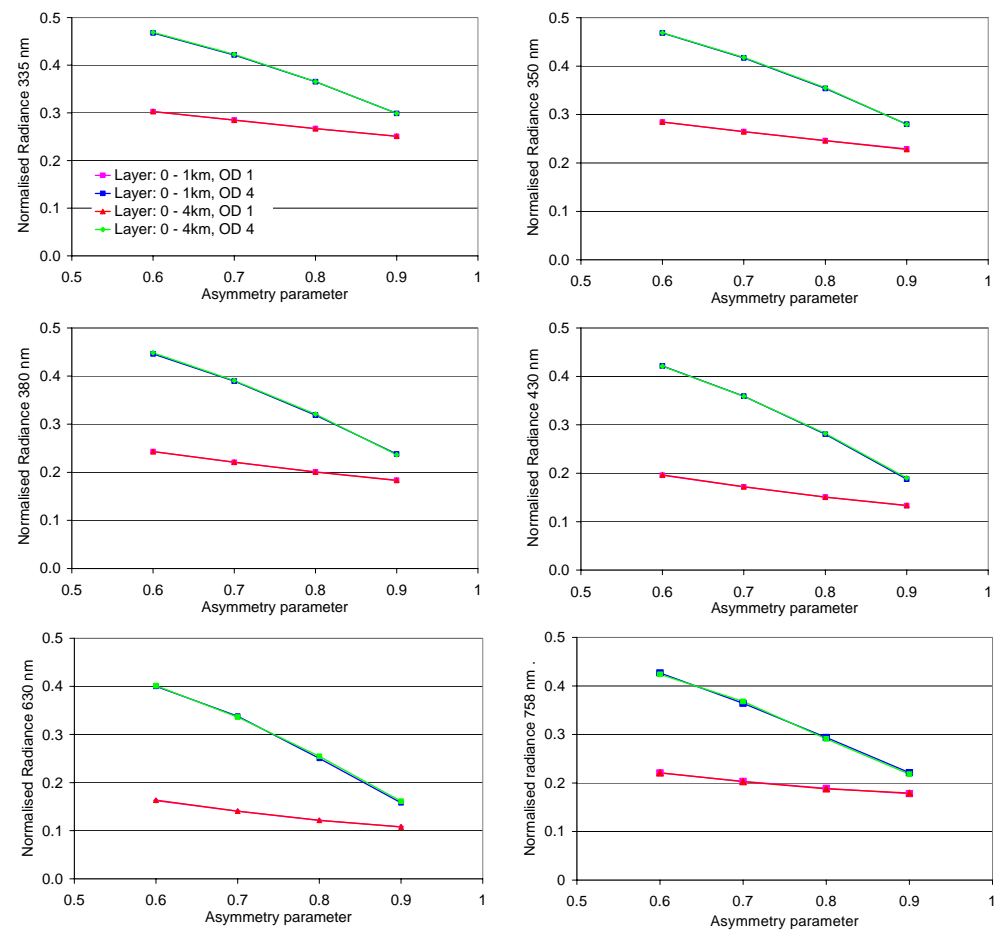

Fig. A8. Dependence of the normalised radiance on the aerosol asymmetry parameter $g$. The calculations are performed for aerosol single scattering albedo of $1, \mathrm{SZA}$ of $30^{\circ}$, and a viewing angle of $-90^{\circ}$ (nadir geometry). For $758 \mathrm{~nm}$ the surface albedo was set to $20 \%$, for $630 \mathrm{~nm}$ to $10 \%$, and for all other wavelengths to $5 \%$. 
on aerosols becomes the dominant effect (compared to scattering at molecules), and the slight increase of Raman scattering with decreasing viewing angle reflects the decreasing probability for aerosol scattering.

The $\mathrm{O}_{4}$ absorption at $360 \mathrm{~nm}$ increases (slightly) with increasing viewing angle. This increase is mainly related to the decreasing probability for molecular scattering with increasing viewing angle (for the selected SZA). If the probability for molecular scattering decreases, effective light paths become longer, leading to larger $\mathrm{O}_{4}$ absorptions.

At the wavelength of the $\mathrm{O}_{2}$ absorption, $630 \mathrm{~nm}$, the probability for Rayleigh scattering is rather small. Most of the observed photons are reflected from the Earth's surface and the atmospheric light path mainly depends on geometry, leading to a mostly symmetrical dependence of $\mathrm{O}_{2}$ absorption on the viewing angle.

In Fig. A3 the simulated normalised radiances are shown as a function of the viewing angle. For most wavelengths and aerosol cases the normalised radiance increases with decreasing viewing angle, indicating the increased probability of molecular (backward) scattering occurring at scattering angles close to $180^{\circ}$. In some cases, different dependencies are found, especially towards larger wavelengths. In these cases effects with other scattering/reflection probabilities like surface reflection or aerosol scattering dominate the measured radiance.

Acknowledgements. We used several external data sets in this study and we want to thank especially the following persons and institutions: Hong-Bin Chen, Philippe Goloub, and Anatoli Chaikovsky for their efforts in establishing and maintaining the Beijing and Minsk AERONET sites. MODIS images were obtained from NASA/GSFC, MODIS Rapid Response, http://aeronet.gsfc.nasa.gov/cgi-bin/bamgomas_interactive. CALIOP data were taken from http://www-calipso.larc.nasa. gov/products/lidar/browse_images/production. We want to thank Ralf Snel and Ilse Aben for fruitful discussions. We thank two anonymous reviewers for their their constructive comments.

The service charges for this open access publication have been covered by the Max Planck Society.

Edited by: O. Torres

\section{References}

Aben, I., Tanzi, C. P., Hartmann, W., Stam, D. M., and Stammes, P.: Validation of Space-Based Polarization Measurements by Use of a Single-Scattering Approximation, with Application to the Global Ozone Monitoring Experiment, Appl. Optics, 42, 36103619, 2003.

Acarreta, J. R., De Haan, J. F., and Stammes, P., Cloud pressure retrieval using the $\mathrm{O}_{2}-\mathrm{O}_{2}$ absorption band at $477 \mathrm{~nm}$, J. Geophys. Res., 109, D05204, doi:10.1029/2003JD003915, 2004.
Boesche, E., Stammes, P., Preusker, R., Bennartz, R., Knap, W., and Fischer, J.: Polarization of skylight in the $\mathrm{O}_{2}$ A band: effects of aerosol properties, Appl. Optics, 47(19), 3467-3480, doi:10.1364/AO.47.003467, 2008.

Bogumil, K., Orphal, J., Homann, T., Voigt, S., Spietz, P., Fleischmann, O. C., Vogel, A., Hartmann, M., Bovensmann, H., Frerik, J., and Burrows, J. P.: Measurements of Molecular Absorption Spectra with the SCIAMACHY Pre-Flight Model: Instrument Characterization and Reference Data for Atmospheric Remote-Sensing in the 230-2380 nm Region, J. Photoch. Photobio. A, 157, 167-184, 2003.

Bovensmann, H., Burrows, J. P., Buchwitz, M., Frerick, J., Noël, S., Rozanov, V. V., Chance, K. V., and Goede, A. H. P.: SCIAMACHY - Mission objectives and measurement modes, J. Atmos. Sci., 56(1), 127-150, 1999.

Burrows, J. P., Hölzle, E., Goede, A. P. H., Visser, H., and Fricke, W.: SCIAMACHY - Scanning Imaging Absorption Spectrometer for Atmospheric Chartography, Acta Astronaut., 35(7), 445, 1995.

Clémer, K., Van Roozendael, M., Fayt, C., Hendrick, F., Hermans, C., Pinardi, G., Spurr, R., Wang, P., and De Mazière, M.: Multiple wavelength retrieval of tropospheric aerosol optical properties from MAXDOAS measurements in Beijing, Atmos. Meas. Tech., 3, 863-878, doi:10.5194/amt-3-863-2010, 2010.

de Beek, R., Vountas, M., Rozanov, V. V., Richter, A., and Burrows, J. P.: The ring effect in the cloudy atmosphere, Geophys. Res. Lett., 28(4), 721-724, 2001.

Deutschmann, T.: Atmospheric radiative transfer modelling using Monte Carlo methods, Diploma thesis, University of Heidelberg, Heidelberg, 2008.

Deutschmann, T. and Wagner, T.: TRACY-II Users manual, http: //joseba.mpch-mainz.mpg.de/Strahlungstransport.htm, last access: December 2010, 2008.

Dubovik, O., Holben, B. N., Eck, T. F., Smirnov, A., Kaufman, Y. J., King, M. D., Tanré, D., and Slutsker, I.: Variability of absorption and optical properties of key aerosol types observed in worldwide locations, J. Atmos. Sci., 59, 590-608, 2002.

Dubuisson, P., Frouin, R., Dessailly, D., Duforêt, L., Leon, J. F., Voss, K., and Antoine, D.: Estimating the altitude of aerosol plumes over the ocean from reflectance ratio measurements in the $\mathrm{O}_{2}$ A-band, Remote Sens. Environ., 113, 1899-1911, 2009.

Grainger J. F. and Ring, J.: Anomalous Fraunhofer line profiles, Nature, 193, 762, 1962.

Greenblatt, G. D., Orlando, J. J., Burkholder, J. B., and Ravishankara, A. R.: Absorption measurements of oxygen between 330 and 1140 nm, J. Geophys. Res., 95, 18577-18582, 1990.

Grzegorski, M.: Cloud retrieval from UV/VIS satellite instruments (SCIAMACHY and GOME), PhD-thesis, University of Heidelberg, Heidelberg, Germany, 2009.

Heidinger, A. K. and Stephens, G. L.: Molecular Line Absorption in a Scattering Atmosphere, Part II: Application to Remote Sensing in the $\mathrm{O}_{2}$ A-Band, J. Atmos. Sci., 57, 1615-1634, 2000.

Henyey, L. and Greenstein, J.: Diffuse radiation in the galaxy, Astrophys. J., 93, 70-83, 1941.

Herman, J. R. and Celarier, E. A.: Earth surface reflectivity climatology at 340-380 nm from TOMS data, J. Geophys. Res., 102, 28003-28011, doi:10.1029/97JD02074, 1997. 
Holben, B. N., Tanre, D., Smirnov, A., Eck, T. F., Slutsker, I., Abuhassan, N., Newcomb, W. W., Schafer, J., Chatenet, B., Lavenue, F., Kaufman, Y. J., Vande Castle, J., Setzer, A., Markham, B., Clark, D., Frouin, R., Halthore, R., Karnieli, A., O’Neill, N. T., Pietras, C., Pinker, R. T., Voss, K., and Zibordi, G.: An emerging ground-based aerosol climatology: Aerosol Optical Depth from AERONET, J. Geophys. Res., 106, 12067-12097, 2001.

Joiner, J. and Bhartia, P. K.: The determination of cloud pressures from rotational Raman scattering in satellite backscatter ultraviolet measurements, J. Geophys. Res., 100, 23019-23026, 1995.

Joiner, J., Bhartia, P. K., Cebula, R. P., Hilsenrath, E., McPeters, R. D., and Park, H.: Rotational Raman scattering - Ring effect in satellite backscatter ultraviolet measurements, Appl. Optics, 34, 4513-4525, 1995.

Joiner, J., Vasilkov, A., Flittner, D., Buscela, E., and Gleason, J.: Retrieval of Cloud Pressure from Rotational Raman Scattering, in: OMI Algorithm Theoretical Basis Document Volume III: Clouds, Aerosols, and Surface UV Irradiance, edited by: Stammes, P., ATBD-OMI-03, Version 2.0, August 2002, http://www.knmi.nl/omi/documents/data/ OMI_ATBD_Volume_3_V2.pdf, last access: December 2010, 31-46, 2002.

Joiner, J., Vasilkov, A. P., Flittner, D. E., Gleason, J. F., and Bhartia, P. K.: Retrieval of cloud pressure and oceanic chlorophyll content using Raman scattering in GOME UV measurements, J. Geophys. Res., 109, D01109, doi:10.1029/2003JD003698, 2004.

Joiner, J. and Vasilkov, A. P.: First results from the OMI rotational Raman scattering cloud pressure algorithm, Geoscience and Remote Sensing, IEEE Transactions, 44(5), 1272-1282, 2006.

Joiner, J., Vasilkov, A. P., Bhartia, P. K., Wind, G., Platnick, S., and Menzel, W. P.: Detection of multi-layer and vertically-extended clouds using A-train sensors, Atmos. Meas. Tech., 3, 233-247, doi:10.5194/amt-3-233-2010, 2010.

Kattawar, G. W., Young, A. T., and Humphreys, T. J.: InelasticScattering in Planetary-Atmospheres, 1. The Ring Effect, without Aerosols, Astrophys. J., 243(3), 1049-1057, 1981.

Kleipool, Q. L., Dobber, M. R., de Haan, J. F., and Levelt, P. F.: Earth surface reflectance climatology from 3 years of OMI data, J. Geophys. Res., 113, D18308, doi:10.1029/2008JD010290, 2008.

Koelemeijer, R. B. A., Stammes, P., Hovenier, J. W., de Haan, J. F.: A fast method for retrieval of cloud parameters using oxygen A band measurements from the Global Ozone Monitoring Experiment, J. Geophys. Res., 106, 3475-3490, 2001.

Koelemeijer, R. B. A., de Haan, J. F., and Stammes, P.: A database of spectral surface reflectivity in the range $335-772 \mathrm{~nm}$ derived from 5.5 years of GOME observations, J. Geophys. Res., 108(D2), 4070, doi:10.1029/2002JD002429, 2003.

Kokhanovsky, A. A., Rozanov, V. V., Burrows, J. P., Eichmann, K.-U., Lotz, W., and Vountas, M.: The SCIAMACHY cloud products: Algorithms and examples from ENVISAT, Adv. Space Res., 36, 789-799, 2005.

Kokhanovsky, A. A., Mayer, B., Rozanov, V. V., Wapler, K., Burrows, J. P., and Schumann, U.: The influence of broken cloudiness on cloud top height retrievals using the nadir observations of backscattered solar radiation in the oxygen A-band, J. Quant. Spectrosc. Ra., 103, 460-477, 2007.

Kokhanovsky, A. A. and Rozanov, V. V.: The determination of the dust cloud altitude from a satellite using hyperspectral measurements in the gaseous absorption band, Int. J. Remote Sens., 31, 2729-2744, 2010.

Koppers, G. A. A., Jansson, J., and Murtagh, D. P.: Aerosol optical thickness retrieval from GOME data in the oxygen A-band, Proc. 3rd ERS symposium on space at the service of our environment, Florence, 14-21 March 1997, ESA SP-414, http://earth. esa.int/workshops/ers97/papers/koppers1/, last access: December 2010, 693-696, 1997.

Krijger, J. M., van Weele, M., Aben, I., and Frey, R.: Technical Note: The effect of sensor resolution on the number of cloud-free observations from space, Atmos. Chem. Phys., 7, 2881-2891, doi:10.5194/acp-7-2881-2007, 2007.

Krotkov, N. A., Bhartia, P. K., Herman, J. R., Slusser, J. R., Scott, G., Labow, G. J., Vasilkov, A. P., Eck, T., Doubovik, O., and Holben, B. N.: Aerosol ultraviolet absorption experiment (2002 to 2004), part 2: absorption optical thickness, refractive index, and single scattering albedo, Opt. Eng., 44, 041005, doi:10.1117/1.1886819, 2005.

Kuze, A. and Chance, K. V.: Analysis of cloud top height and cloud coverage from satellites using the $\mathrm{O}_{2} \mathrm{~A}$ and $\mathrm{B}$ bands, J. Geophys. Res., 99, 14481-14491, 1994.

Landgraf, J., Hasekamp, O., van Deelen, R., and Aben, I.: Rotational Raman scattering of polarized light in the Earth atmosphere: a vector radiative transfer model using the radiative transfer perturbation theory approach, J. Quant. Spectrosc. Ra., 87, 399-433, 2004.

Langford, A. O., Schofield, R., Daniel, J. S., Portmann, R. W., Melamed, M. L., Miller, H. L., Dutton, E. G., and Solomon, S.: On the variability of the Ring effect in the near ultraviolet: understanding the role of aerosols and multiple scattering, Atmos. Chem. Phys., 7, 575-586, doi:10.5194/acp-7-575-2007, 2007.

Levelt, P. F., Hilsenrath, E., Leppelmeier, G. W., van den Oord, G. H. J., Bhartia, P. K., Tamminen, J., de Haan, J. F., and Veefkind, J. P.: Science Objectives of the Ozone Monitoring Instrument, IEEE T. Geosci. Remote, 44(5), 1199-1208, doi:10.1109/TGRS.2006.872336, 2006.

Lichtenberg, G., Kleipool, Q., Krijger, J. M., van Soest, G., van Hees, R., Tilstra, L. G., Acarreta, J. R., Aben, I., Ahlers, B., Bovensmann, H., Chance, K., Gloudemans, A. M. S., Hoogeveen, R. W. M., Jongma, R. T. N., Noël, S., Piters, A., Schrijver, H., Schrijvers, C., Sioris, C. E., Skupin, J., Slijkhuis, S., Stammes, P., and Wuttke, M.: SCIAMACHY Level 1 data: calibration concept and in-flight calibration, Atmos. Chem. Phys., 6, 5347-5367, doi:10.5194/acp-6-5347-2006, 2006.

Meller, R. and Moortgat, G. K.: Temperature dependence of the absorption cross sections of formaldehyde between 223 and $323 \mathrm{~K}$ in the wavelength range $225-375 \mathrm{~nm}$, J. Geophys. Res., 105, 7089-7101, 2000.

Mishchenko, M. I., Lacis, A. A., and Travis, L. D.: Errors induced by the neglect of polarization in radiance calculations for Rayleigh-scattering atmospheres, J. Quant. Spectrosc. Ra., 51, 491-510, doi:10.1016/0022-4073(94)90149-X, 1994.

Noël, S.: Determination of Correction Factors for SCIAMACHY Radiances and Irradiances, technical documentation, Institute for Environmental Physics, University of Bremen, Document number: IFE-SCIA-SN-20050203_IrrRadCorrection, http://www. iup.physik.uni-bremen.de/sciamachy/SCIA_CAL/irrad_corr.pdf, last access: December 2010, 2005. 
Park, H., Heath, D. F., and Mateer, C. L.: Possible application of the Fraunhofer line filling in effect to cloud height measurements, Meteorological Optics, OSA Technical Digest Series, Opt. Soc. Am., Washington, DC, 70-81, 1986.

Penning de Vries, M. J. M., Beirle, S., and Wagner, T.: UV Aerosol Indices from SCIAMACHY: introducing the SCattering Index (SCI), Atmos. Chem. Phys., 9, 9555-9567, doi:10.5194/acp-99555-2009, 2009.

Platt, U. and Stutz, J.: Differential Optical Absorption Spectroscopy, Principles and Applications, Springer, Berlin, 2008.

Rothman, L. S., Jacquemart, D., Barbe, A., Benner, D. C., Birk, M., Brown, L. R., Carleer, M. R., Chackerian Jr., C., Chance, K., Coudert, L. H., Dana, V., Devi, V. M., Flaud, J.-M., Gamache, R. R., Goldman, A., Hartmann, J.-M., Jucks, K. W., Maki, A. G., Mandin, J.-Y., Massie, S. T., Orphal, J., Perrin, A., Rinsland, C. P., Smith, M. A. H., Tennyson, J., Tolchenov, R. N., Toth, R. A., Vander Auwera, J., Varanasi, P., and Wagner, G.: The HITRAN 2004 molecular spectroscopic database, J. Quant. Spectrosc. Ra., 96, 139-204, 2005.

Shefov, N. N.: Spectroscopic, photoelectric, and radar investigations of the aurora and the nightglow, Izd. Akad. Nauk., 1, 1959.

Slijkhuis, S.: SCIAMACHY level 0 to $1 \mathrm{c}$ processing algorithm theoretical basis document, Tech. Note ENV-ATB-DLR-SCIA0041, Dtsch. Zent. für Luft- und Raumfahrt, Oberpfaffenhofen, Germany, 1999.

Solomon, S., Schmeltekopf, A. L., and Sanders, R. W.: On the interpretation of zenith sky absorption measurements, J. Geophys. Res., 92, 8311-8319, 1987.

Spurr, R., de Haan, J., van Oss, R., and Vasilkov, A.: Discreteordinate radiative transfer in a stratified medium with first-order rotational Raman scattering, J. Quant. Spectrosc. Ra., 109(3), 404-425, doi:10.1016/j.jqsrt.2007.08.011, 2008.

Stephens, G. L. and Heidinger, A. K.: Molecular line absorption in a scattering atmosphere, Part I: Theory. J. Atmos. Sci., 57, 15991614, 2000.

United States Committee on Extension to the Standard Atmosphere, US Standard Atmosphere, 1976, National Oceanic and Atmospheric Administration, National Aeronautics and Space Administration, United States Air Force, Washington, DC, 1976.

van Deelen, R., Hasekamp, O. P., van Diedenhoven, B., and Landgraf, J.: Retrieval of cloud properties from near ultraviolet, visible and near infrared satellite-based Earth reflectance spectra: a comparative study, J. Geophys. Res., 113, D12204, doi:10.1029/2007JD009129, 2008.
Vandaele, A. C., Hermans, C., Simon, P. C., Carleer, M., Colin, R., Fally, S., Merienne, M. F., Jenouvrier, A., and Coquart, B.: Measurements of the $\mathrm{NO}_{2}$ absorption cross-section from $42000 \mathrm{~cm}^{-1}$ to $10000 \mathrm{~cm}^{-1}(238-1000 \mathrm{~nm})$ at $220 \mathrm{~K}$ and 294 K, J. Quant. Spectrosc. Ra., 59, 171-184, 1998.

Vasilkov, A. P., Joiner, J., Gleason, J., and Bhartia, P. K.: Ocean Raman scattering in satellite backscatter UV measurements, Geophys. Res. Let., 29, 1833, doi:10.1029/2002GL014955, 2002.

Vasilkov, A. P., Joiner, J., Bhartia, P. K., Torres, O., and Spurr, R.: Using Rotational Raman Scattering in the Atmosphere for Satellite Retrieval of the Aerosol Plume, AGU Spring Meeting Abstracts, http://adsabs.harvard.edu/abs/2006AGUSM.A34A..02V, last access: December 2010, 2006.

Vountas, M., Richter, A., Wittrock, F., and Burrows, J. P.: Inelastic scattering in ocean water and its impact on trace gas retrievals from satellite data, Atmos. Chem. Phys., 3, 1365-1375, doi:10.5194/acp-3-1365-2003, 2003.

Wagner, T., Heland, J., Zöger, M., and Platt, U.: A fast $\mathrm{H}_{2} \mathrm{O}$ total column density product from GOME - Validation with insitu aircraft measurements, Atmos. Chem. Phys., 3, 651-663, doi:10.5194/acp-3-651-2003, 2003.

Wagner, T., Beirle, S., Deutschmann, T., Grzegorski, M., and Platt, U.: Satellite monitoring of different vegetation types by differential optical absorption spectroscopy (DOAS) in the red spectral range, Atmos. Chem. Phys., 7, 69-79, doi:10.5194/acp-769-2007, 2007.

Wagner, T., Beirle, S., Deutschmann, T., Grzegorski, M., and Platt, U.: Dependence of cloud properties derived from spectrally resolved visible satellite observations on surface temperature, Atmos. Chem. Phys., 8, 2299-2312, doi:10.5194/acp-8-2299-2008, 2008.

Wagner, T., Beirle, S., and Deutschmann, T.: Three-dimensional simulation of the Ring effect in observations of scattered sun light using Monte Carlo radiative transfer models, Atmos. Meas. Tech., 2, 113-124, doi:10.5194/amt-2-113-2009, 2009a.

Wagner, T., Deutschmann, T., and Platt, U.: Determination of aerosol properties from MAX-DOAS observations of the Ring effect, Atmos. Meas. Tech., 2, 495-512, doi:10.5194/amt-2-4952009, 2009b.

Wilmouth, D. M., Hanisco, T. F., Donahue, N. M. and Anderson, J. G.: Fourier Transform Ultraviolet Spectroscopy of the $A^{2} \Pi_{3 / 2}<-X^{2} \Pi_{3 / 2}$ Transition of BrO, J. Phys. Chem., 103, 8935-8944, 1999.

Winker, D. M., Vaughan, M. A., Omar, A., Hu, Y., Powell, K. A., Liu, Z., Hunt, W. H., and Young, S. A.: Overview of the CALIPSO Mission and CALIOP Data Processing Algorithms, J. Atmos. Ocean. Tech., 26, 2310-2323, 2009. 